Universidad Politécnica de Madrid

Escuela Técnica Superior de Ingenieros de

Telecomunicación

\title{
ETSUPM
}

\section{CONTEXTO, CRIPTOANÁLISIS Y PROPUESTA DE SOLUCIÓN DE LA INSCRIPCIÓN DE LA TALLA (ORIGINAL) \\ DE LA VIRGEN DE CANDELARIA \\ DE TENERIFE \\ (CANARIAS, ESPAÑA) \\ Tesis Doctoral}

\section{Vicente Jara Vera}

Ingeniero de Telecomunicación

2016 

Departamento de Matemática Aplicada a las Tecnologías de la Información y las Comunicaciones

\section{ETSUPM}

\section{CONTEXTO, CRIPTOANÁLISIS Y PROPUESTA DE SOLUCIÓN DE LA INSCRIPCIÓN DE LA TALLA (ORIGINAL) DE LA VIRGEN DE CANDELARIA DE TENERIFE (CANARIAS, ESPAÑA)}

Vicente Jara Vera Ingeniero de Telecomunicación

DIRECTORA

Carmen Sánchez Ávila

2016 



\section{TRIBUNAL CALIFICADOR}

Tribunal nombrado por el Magfco. y Excmo. Sr. Rector de la Universidad

Politécnica de Madrid el día de

de

Presidente Dr. D.

Vocal Dr. D.

Vocal Dr. D.

Vocal Dr. D.

Secretario Dr. D.

Realizado el acto de lectura y defensa de la Tesis el día de de en Madrid.

\section{Calificación:}

EL PRESIDENTE

EL SECRETARIO

LOS VOCALES 


La creencia de que existen entidades como la física, la biología o la arqueología, $y$ de que estos "estudios" o "disciplinas" se distinguen por el tema que investigan me parece un residuo [...]. Sostengo que los objetos de estudio, o tipos de cosa, no constituyen una base para diferenciar disciplinas. Las disciplinas se diferencian en parte por razones históricas y por conveniencia administrativa [...]. Pero todas estas clasificaciones y distinciones son relativamente poco importantes y superficiales. No estudiamos temas, sino problemas; y los problemas pueden atravesar los límites de cualquier objeto de estudio o disciplina. [...] La solución de los problemas puede atravesar las fronteras de muchas ciencias.

Karl Raimund Popper (1902-1994). "Conjeturas y refutaciones" 



\section{AGRADECIMIENTOS}

En esta página de agradecimientos no va a haber una lista de personas, es más, no va a haber más que una persona, y no porque no haya que agradecer a nadie más nada, pues aquellos que hubieran esperado encontrarse aquí deberán buscarse en la sección bibliográfica o saber que por ellos accedí a algunas de esas obras. Ese es el mayor reconocimiento, pues esta obra no sería posible sin los miles y miles de otros trabajos consultados durante varios años.

El agradecimiento de esta página va dirigido a quien ha hecho posible que haya podido hacer todo lo anterior, permitiéndome lo que nadie jamás hubiera consentido y que para mí es lo más valioso: el silencio y la tranquilidad para investigar con total libertad. Esto, así dicho, parece simple, pero en el mundo académico no se fomenta, no se consiente ni permite, y la verdad es que se impide. En ninguna universidad del mundo hubiera podido presentar una tesis así; hubiera sido cercenada, recortada y focalizada al área de trabajo del departamento propio, impidiendo una amplitud de investigación en diversas disciplinas y una libertad de pensamiento que yo he podido tener. Es más, la dedicación a la resolución de un problema con seis siglos de antigüedad por parte de un doctorando, de inicio, es una propuesta que cualquier director de tesis descartaría para realizarse. Yo, si fuera tal director de tesis, lo desaconsejaría para mi doctorando. Le pediría que recondujera y recortara sus ambiciones y amplitud y se limitara a algo factible y alcanzable.

Son muchos los años que conozco a mi directora de tesis. Con ella hice mi Proyecto Final de Carrera en temas criptográficos, y ahí pude conocer su forma de trabajar y ella el mío. Ella me conoce y yo la conozca a ella. Ella elige a sus doctorandos y yo elijo también a mi director de tesis. Nos elegimos el uno al otro, y he de decir que por mi parte la elegí porque solamente con ella podía hacer esta tesis, u otra del ámbito algebraico y criptológico cual fue la primera, relato que posteriormente extenderé en el prefacio, igualmente descabellada y desaconsejable. Su absoluto amparo, su continuo bloqueo de cualquier incomodidad y distracción sobre mi trabajo, la comprensión ante mis peculiares formas de ser y mis métodos de trabajo, mis ausentes localizaciones y mis silencios ha sabido entenderlos a la perfección, conociendo que solamente de estos otoños e inviernos de circunspección y sigilo vendría mucho más.

Se escucha que la universidad española no hace investigación. Puedo decir que conozco multitud de investigaciones en diversas disciplinas en muchas universidades de todo el mundo, muchas de ellas en el más alto puesto de los diferentes rankings. Yo, personalmente, en la Universidad Politécnica de Madrid, en la Escuela Técnica Superior de Ingenieros de 
Telecomunicación, creo que he podido hacerlo, y lo avalo con mi investigación de tesis. E igualmente me reafirmo en que en ninguna universidad y con ningún director de tesis hubiera podido realizarla.

Por todo ello, y sin más palabras, mi mayor agradecimiento, gratitud cordial e intelectual, es para Carmen Sánchez Ávila, mi directora de tesis, de manera única, para así mejor destacar y resaltar mi inmenso reconocimiento. 



\section{Índice general}

$\begin{array}{ll}\text { AGRADECIMIENTOS } & 11\end{array}$

INTRODUCCIÓN 1

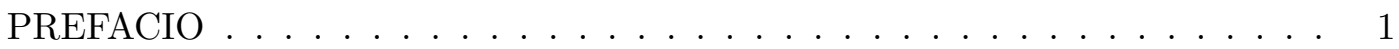

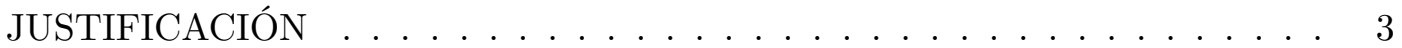

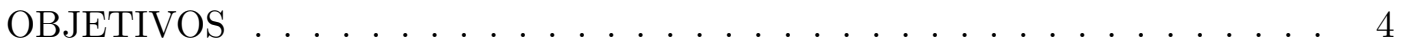

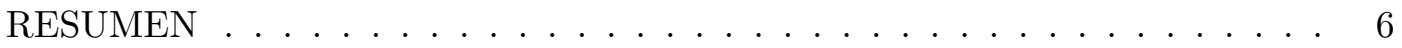

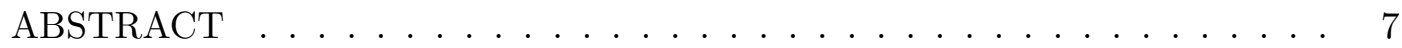

ESTRUCTURA Y DESCRIPCIÓN DE LOS CAPÍTULOS . . . . . . . . . 8

METODOLOGÍA . . . . . . . . . . . . . . . . . . . 10

1 Las fuentes documentales textuales de la talla (original) de la Virgen $\begin{array}{lr}\text { de Candelaria } & 11\end{array}$

1.1 Objetivo del capítulo . . . . . . . . . . . . . . . . . . . . 11

1.2 Introducción . . . . . . . . . . . . . . . . . . . . . 12

1.3 Fray Alonso de Espinosa, O.P. y su "Del origen y milagros de la Santa Imagen de nuestra Señora de Candelaria, que apareció en la Isla de Tenerife, con la descripción de esta Isla" $(1594)$. . . . . . . . . . . . . . . 13

1.4 Conclusiones . . . . . . . . . . . . . . . . . . . . 13

1.4.1 La posible fecha de la aparición de la talla según las fuentes documentales

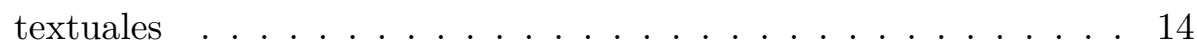

1.4.2 El posible texto inscrito de la talla según las fuentes documentales textuales ......................... 15

2 CONCLUSIONES $\quad \mathbf{2 7}$

2.1 LÍNEAS FUTURAS . . . . . . . . . . . . . . . . . . . . . . 28

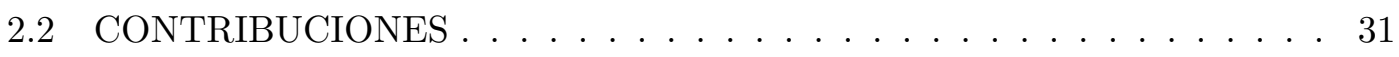




\section{Índice de figuras}

1.1 Mural del altar mayor de la actual basílica de Nuestra Señora de Candelaria (Tenerife) (Canarias, España) con la nueva talla en el centro y motivos terrenales (plano inferior) y celestiales (plano superior). José Aguiar y García (1895-1976), 1959[?]. (Foto del autor). . . . . . . . . . . . . . 12

1.2 Cuadro resumen de fechas de aparición de la talla original de Candelaria según las fuentes documentales textuales presentadas en este capítulo. . . 14

1.3 Comparativa entre los materiales documentales textuales acerca de las letras de la talla de la Virgen de Candelaria. . . . . . . . . . . . . . . . . . 24

1.4 Comparativa entre los materiales documentales textuales entre sí en sus variantes-similares/ausencias-inserciones (rojo/azul) acerca de las letras de la talla de la Virgen de Candelaria. . . . . . . . . . . . . . . . . . 25 


\section{INTRODUCCIÓN}

\section{PREFACIO}

A finales de diciembre del año 2010 cometí un error. He aprendido con el paso de los años que hay libros que no debo leer más que diagonalmente, artículos científicos que solamente he de ojear por encima, noticias que simplemente debo de mirar en sus titulares y en sus letras tipográficas resaltadas en negrita. Nada más. No he de hacerlo porque difícilmente podría frenarme si algo de ello captara, o mejor, raptara, mi interés.

En día 1 de noviembre de 2010 recibí uno de los boletines digitales que durante muchos años edita D. Arturo Quirantes Sierra (1966- ), gran divulgador científico, profesor de Física en la Universidad de Granada y buen conocedor de la criptografía. El boletín tiene por nombre "ENIGMA", en reconocimiento a... (es obvio, y si no te lo parece no deseo quitarte tu tiempo, no merece la pena que sigas leyendo).

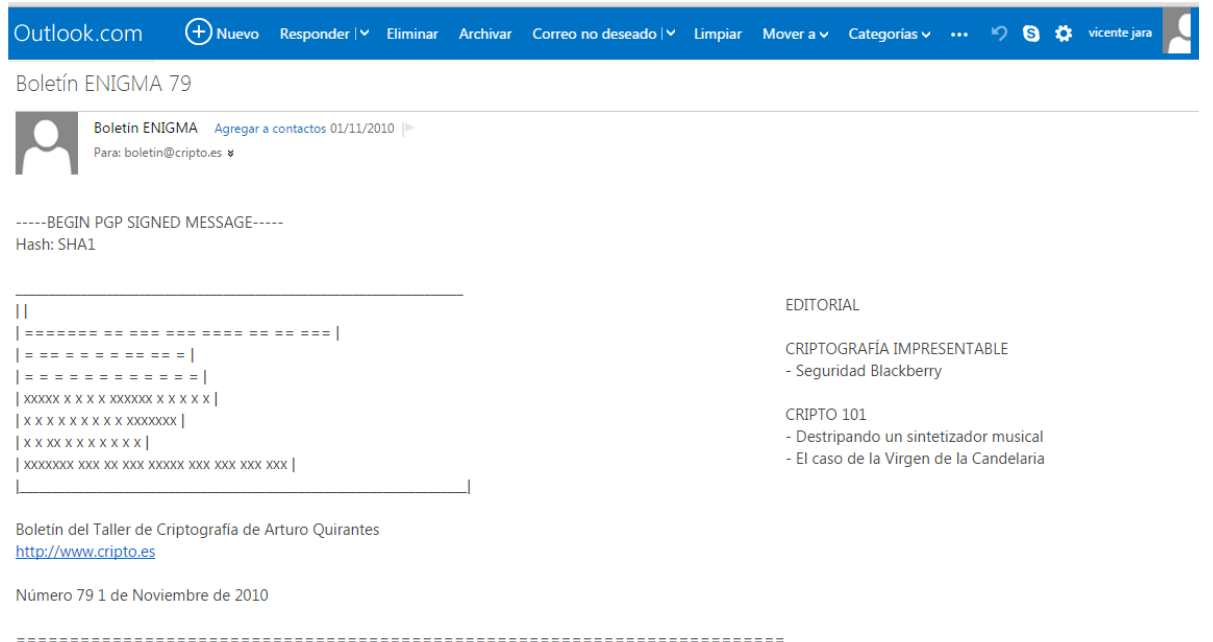

En aquel momento yo venía desarrollando durante varios años diversas investigaciones referentes al criptoanálisis algebraico de la familia SHA de funciones hash, con resultados creo que prometedores, y en la que lograba una ampliación de métodos de ataque incorporando el uso de herramientas del cálculo para resolver problemas de funciones booleanas. Sin embargo, el día 22 de diciembre recuerdo haber revisado el correo recibido el día 1 de noviembre pasado y mi atención se dirigió al artículo final, 
"El caso de la Virgen de la Candelaria"[?]. Yo sabía de la existencia de esta advocación, de esta talla, de este santuario, atendido por los frailes de la Orden de Predicadores (dominicos) en las islas Canarias, en concreto, en la localidad tinerfeña de Candelaria. Lo que no sabía era que la talla actual no es la original. Lo que desconocía es la existencia de unos extraños letreros en la primigenia. Lo que no imaginaba era que tras alrededor de 600 años ese texto seguía sin esclarecerse. Tras leer las algo más de cuatro páginas de este artículo donde se hacían una serie de comentarios expositivos y algunas deducciones someras, si bien correctamente orientadas, que le hacían pensar a su autor en no ser un texto cifrado y dejando varios interrogantes, el artículo finalizaba de la siguiente manera: "Por mi parte, caso cerrado. Se levanta la sesión". Y entonces el que se sentó fui yo. Dos días más tarde, y tras hacer mis propias indagaciones, en la mañana de Nochebuena, sabía que alcanzaría una solución.

Aún pasarían seis meses más hasta el verano del año 2011, en que pensé resolverlo durante los meses de julio y agosto y escribir un artículo científico para ser publicado. Mientras tanto seguía con mi anterior tesis de criptoanálisis de funciones hash. Durante los meses veraniegos y tras ir recopilando material sobre la talla de Candelaria pude comprender que el problema era mucho mayor de lo que imaginaba, con multitud de aristas y complejidades, muchas de ellas no resueltas y ni siquiera consideradas. Mi artículo científico empezó a crecer y a perder sus dimensiones primeras. Durante alrededor de un año dos tesis se superponían en mi mesa de trabajo y en mi mente. Había que tomar una decisión pues ambas llevarían varios años de trabajo. La Virgen María venció. 


\section{JUSTIFICACIÓN}

Con todo lo dicho ya en estas primeras páginas es nítida la respuesta al por qué esta investigación: no conocemos el significado de un texto de hace seis siglos; un simple texto que casi no llega a 200 letras latinas mayúsculas se ha resistido hasta el día de hoy a todos los intentos por soltar o dejar escapar su significado.

Es más, no conocemos demasiado de las circunstancias de la talla en la que se inscribió, todo ello está envuelto en cierto halo de leyenda, que el tiempo, la memoria y la desmemoria han configurado y dado forma en otras posibilidades y relatos a veces contrapuestos. Incluso no sabemos quién la mandó hacer, y algunos aún la consideran aparecida por arte milagroso en las playas de Tenerife.

Además, los aspectos artísticos de la misma talla no son comunes al resto de obra escultórica en madera coetánea, y hay algo en ella que nos hace pensar en propósitos genuinos y propios. Una talla que, si queríamos más misterio, no existe ya, sino que en un terrible temporal como nunca sufrieron los pobladores de la isla de Tenerife ocurrido en el año 1826, desapareció.

Han sido numerosos los intentos por encontrar el significado de dicha inscripción por personas de todo tipo y condición, las más de las veces vecinos del archipiélago canario, unas veces como admiradores del personaje de María, a quien representa la talla de Candelaria, o bien simpatizantes propios y ajenos de las islas, cuando no de la historia canaria pasada. En ocasiones el intento ha sido más serio y sostenido, involucrando a los grandes sabios de las épocas pasadas, recientes y actuales, los más esclarecidos entre los doctos y versados en historia, religión, lenguas, juegos lingüísticos y desciframiento, o en todo y más a la vez.

Cuando algo tan antiguo se muestra tan inexpugnable y además ha resistido el ataque y abordaje de tantas mentes lúcidas e ilustradas solo cabe la reverencia ante el misterio y la admiración hacia los cofrades y compañeros que en tantas horas, días, meses o años, con arduo empeño se dispusieron a conocer tan esquivo texto y tanto aportaron, y aún espero sigan proporcionando, a dicha solución. 


\section{OBJETIVOS}

Nuestra investigación se inició con el objetivo de conocer si el texto inscrito en la talla original de la Virgen de Candelaria era un texto cifrado. ¿Acaso se puede esto saber con certeza? ¿No quedará alguna duda de ello, en especial si todos los métodos y sistemas probados uno tras otro, no obtuvieran como resultado un texto en claro con significado? ¿Qué significa exactamente eso de todos los métodos y sistemas? ¿Cómo sabremos si hemos analizado todas las posibilidades de cifrado y criptoanalizado sobre un método incierto el conjunto de letras de la talla mariana? Pero antes, ¿conocemos realmente qué letras son exactamente si la talla se ha perdido hace doscientos años? Estas son varias preguntas, y no son fáciles de responder. Y ellas fueron el inicio de nuestro estudio. Y de ellas daremos y rendiremos cuentas a lo largo de esta tesis.

Así, inicialmente se ha de conocer cuáles son las más fieles y fidedignas letras que tenía la imagen original. Esto significa un análisis de fuentes textuales escritas y de obra artística diversa, que recogen, con múltiples variantes, dicha cartelería.

Tras dilucidad este primer aspecto y circunscribirnos a un texto de alta certeza como primigenio, empieza el primero de los análisis, por otro lado nada claro, cual es intentar suponer la lengua base del texto original. Se deberá empezar por las más probables, como es el latín, idioma litúrgico típico de los siglos XIV y XV, añadiendo el castellano, el catalán en sus zonas septentrionales y meridionales levantinas, así como en la forma balear. Además, considerar las lenguas italianas e incluso en el francés, idiomas que el contexto del redescubrimiento del archipiélago parece apoyar. La extensión lingüística se extenderá hasta llegar al centenar de lenguas en todos los filos posibles de Europa, África, y amplia parte de Asia.

Sigue al examen de la lengua base un recorrido histórico de todos los métodos posibles de cifrado que se pudieran haber utilizado. Con ello se someterá el texto a todos los sistemas y métodos posibles con la mayor meticulosidad y exhaustividad posible, como jamás se ha sometido a ningún texto antes en toda la historia de la criptología. En este momento se alcanza el objetivo inicial planteado, con el resultado de que nuestro texto no está cifrado, no es el resultado de ningún método criptológico ni esteganológico de ocultación.

Pero si no está cifrado y no tiene un sentido claro en su lectura, ¿acaso es algo aleatorio o sin sentido, una suerte de letras colocadas sin mayor interés que el estético o el de una broma dejada a la posteridad? El objetivo inicial se amplía y deriva en este instante en intentar ver si el texto, que se niega a estar cifrado y que no encajaba en ninguna de las 101 lenguas analizadas, incluido el guanche y 26 lenguas del Filo Afroasiático, con amplio espectro de la Familia Bereber, etnia de procedencia de los aborígenes isleños, es un texto pseudo-aleatorio. El resultado vuelve a sorprendernos, pues mostrará no serlo, es más, vuelve a indicarnos una dirección lingüística.

A partir de entonces, e intuyendo ser el texto un conjunto grafémico de una lengua, como en ocasiones ha ocurrido en la historia del criptoanálisis, el cifrado se mezcla con el descifrado de lenguas, en este caso de lenguas arcaicas bereberes que habrá que rescatar 
con los pocos datos disponibles e intentar postular si nos encontramos ante un texto en una lengua extinta y de trazas y rastros bereberes que nuestro análisis de lenguas previo, y debido a la fuerte arabeización de la Familia Bereber desde el siglo IX en adelante, no pudo detectar.

El objetivo final será situar el texto en esta lengua y con ello ofrecer una propuesta de solución del mismo, dando un significado que el contexto isleño, de redescubrimiento europeo, el encuentro de culturas y de religiones, líbicas e insulares amazigh y cristianas, sostenga argumentalmente y de manera coherente, una solución congruente y razonable al conjunto de letras inscritas en la talla original de la Virgen de Candelaria de Tenerife, en el archipiélago de las Canarias. 


\section{RESUMEN}

Esta investigación es un ejemplo de simbiosis entre criptoanálisis y desciframiento de lenguas. Es la búsqueda del sentido de una inscripción, un conjunto de casi doscientas letras latinas, en una talla de la Virgen María que estaba en la isla de Tenerife, en la localidad hoy de Candelaria, en las islas Canarias. La imagen desapareció en un temporal en el año 1826. No obstante, es posible lograr una gran certeza sobre qué letras tenía, acudiendo a las fuentes documentales textuales y artísticas.

El conocimiento del significado, si lo hubiera, de la inscripción mariana, creemos que no puede lograrse sin la adecuada comprensión del contexto. Esto significa indagar en la historia de la misma talla, que se remonta hasta el siglo XIV o XV, en el estudio de la población autóctona canaria, así como de los pueblos que allí llegaron en sus diferentes momentos históricos. Además, es necesario conocer el redescubrimiento del archipiélago canario y sus procesos de conquista y evangelización. Todos estos datos irán ofreciendo un panorama nuevo y sorprendente para comprender no sólo las letras sino la misma imagen escultórica en madera.

A partir de este momento la indagación se moverá en ver si las letras corresponden a alguna lengua posible, lo que nos ha llevado a analizar un amplísimo conjunto de textos lo más cercanos a la época bajo estudio, pertenecientes a alrededor de un centenar de lenguas. Tras el examen lingǘstico se ha procedido a un estudio de las posibles formas criptográficas que se hubieran utilizado para generar el texto de la inscripción. Se ofrece un detallado y minucioso elenco de técnicas posibles que pudieran haberse adoptado y se criptoanaliza con exhaustividad las letras de la talla mariana. Al mismo tiempo se ofrece un nuevo marco criptológico de métodos y sistemas más ordenado y completo que el que hasta ahora venía considerándose, en especial desde el surgimiento de la criptografía de clave asimétrica. Continuamos la investigación sopesando la posible generación pseudo-aleatoria del texto, un texto que pudiera no tener sentido alguno.

En este momento, y habiendo completado todas las posibilidades e hipótesis, habiéndose negado todas, volvemos a reconsiderar el cuerpo de conjeturas y supuestos. Desde ahí analizamos en profundidad el ámbito etnográfico y lingüístico bereber como hipótesis más plausible y probable. Tras la profundización en esta lengua y la corrección de los errores que nos llevaron a no detectarla en nuestro análisis precedente, llegamos a la conclusión de encontrarnos ante una lengua arcaica bereber, un conjunto de letras pertenecientes a una lengua y familia hoy no desaparecida, si bien muy modelada y difuminada por otras lenguas, en especial el árabe. Esto nos llevará a rescatar aspectos léxicos, morfológicos, sintácticos y fonéticos de este habla arcaica.

Con todos estos datos realizamos un amplio estudio semántico de la talla tanto desde la perspectiva aborigen autóctona como cristiana.

Finalmente, desde las voces lexicales y sus raíces de las lenguas bereberes e insulares amazigh, ofrecemos el significado de las letras inscritas en la talla mariana de Candelaria. 


\begin{abstract}
This research is an example of symbiosis between cryptanalysis and deciphering of languages. It is the search for meaning in an inscription, a group of about two hundred latin letters on a carving of the Virgin Mary that was on the island of Tenerife, in the town of Candelaria today, in the Canary islands. The image disappeared in a storm in 1826. However, it is possible to achieve a great certainty about what letters had, going to the textual and artistic documentary sources.
\end{abstract}

The knowledge of the meaning, if any, of the marian inscription, can not be achieved without an adequate knowledge of the context. This means researching into the history of the same carving, which dates back to the fourteenth and fifteen century; the study of the canarian indigenous people and of the people who came there at different historical moments. Furthermore, it is necessary to know the rediscovery of the Canary islands and their processes of conquest and evangelization. All these data will offer a new and surprising outlook to understanding not only the letters but the same wood sculpture.

From this moment the inquiry will move to see if the letters correspond to any possible language, which has led us to analyze a very large set of texts as close to the time under study, in a hundred languages. After the language examination, has been carried out a study of possible cryptographic forms used to generate the text of the inscription. A detailed and thorough list of possible techniques that could be adopted is offered. Then exhaustively we cryptanalyze the letters of the marian carving. At the same time a new crypto framework of methods and systems more orderly and complete, especially since the emergence of asymmetric key cryptography, is provided. We continue researching the possible pseudo-random generation of the text, a text that would not make any sense.

At this time, and having completed all the possibilities and hypotheses, all having refused, we return to rethink our assumptions. From there we analyze in depth the ethnographic and linguistic berber sphere as the most likely hypothesis. Following the deepening of this language and correcting the mistakes that led us not to detect it in our analysis above, we conclude that this is an archaic berber language, a set of letters belonging to a language and family not extinct today but very modeled and influenced by other languages, primarily arabic. This will lead us to rescue lexical, morphological, syntactic and phonetic aspects of this archaic speech.

With all this data we make a wide semantic study of the carving from the indigenous and christian perspective.

Finally, from the lexical voices and roots of the berber languages amazigh and island-amazigh, we give the meaning of the letters inscribed in the marian carving of Candelaria. 


\section{ESTRUCTURA Y DESCRIPCIÓN DE LOS CAPÍTULOS}

Comentamos la estructura de la tesis haciendo un resumen capítulo por capítulo de la misma:

En los dos capítulos primeros se recogen las fuentes documentales textuales (capítulo I. "Las fuentes documentales textuales de la talla (original) de la Virgen de Candelaria") y artísticas (capítulo II. "Las fuentes documentales artísticas de la talla (original) de la Virgen de Candelaria") que a lo largo del tiempo han mencionado la talla original de la Virgen de Candelaria de Tenerife, en especial su aparición, lugar y momento, además del conjunto de circunstancias ligadas a ello, junto con la referencia a las inscripciones o letras que la acompañan en su talla.

La talla original de Candelaria desapareció en un aluvión o temporal ocurrido en los días del 7 al 8 de noviembre del año 1826. Debido a la importancia de disponer de la imagen para su examen, se dedica un capítulo a intentar ver qué posibilidades hay de encontrarla, de ahí que en el capítulo III, "La situación actual de la talla (original) de la Virgen de Candelaria", se analice el paradero actual de la talla, reconstruyendo los hechos de aquel fatídico día en que fuera perdida y conjeturando su situación a día de hoy.

Ante la conclusión de su pérdida irrecuperable se delimita con los dos capítulos precedentes el material léxico que será la base del resto de la tesis, un muy probable conjunto de letras que muy presumiblemente sean las originalmente inscritas en la talla de Candelaria.

En el capítulo IV, "El contexto histórico, cultural y religioso", se recogen datos relativos al conocimiento que se tenía de las islas Canarias desde la Antigüedad hasta el redescubrimiento y conquista, así como a la cristianización y los modos evangelizadores en el archipiélago, con el fin de situar bajo ellos la talla mariana. Los datos de contexto son fundamentales para poder descifrar un texto desconocido, por lo que intentaremos responder aquí a las preguntas fundamentales, ofreciendo una serie de respuestas espacio-temporales para la imagen (dónde y cuándo apareció) así como de causalidad final y eficiente (para qué y por quién se mandó hacer).

En el capítulo V, "Las posibles lenguas base de la inscripción", empieza propiamente dicho el análisis criptoanalítico, tratando de encontrar la lengua en la que fueron escritas las enigmáticas inscripciones. Para ello haremos una recopilación lingüística y literaria, ya grafémica como fonética, de amplio y extenso material, capaz de permitirnos establecer su ubicación. En el siguiente capítulo, capítulo VI, "Análisis de las posibles lenguas base de la inscripción", se realiza un examen del material precedente, su suficiencia, su adecuación, así como el análisis de los gramas (grafemas y fonemas), tanto en distancias como por medio del Índice de Coincidencia, según dos metodologías, con mayor y menor filtrado, para situar el texto de la talla en alguna lengua posible.

En el capítulo VII, “Análisis criptoanalítico y esteganolítico”, se exponen 
primeramente todos los métodos conocidos históricamente hasta el momento de la talla de Candelaria, ofreciendo seguidamente un exhaustivo análisis de todas las posibles opciones de cifrado y esteganografía que pudieran haberse aplicado a la inscripción, ofreciendo además una nueva ordenación de métodos y sistemas criptológicos, que consideramos más coherente y compacta a las hoy consideradas. Le sigue el capítulo VIII, "Capítulo intermedio. Recopilación y análisis de aleatoriedad", donde tras haberse concluido en los dos precedentes la no pertenencia de los textos de la imagen a lengua alguna ni haber sido objeto de cifrado o método de ocultación alguno, se examina la posibilidad de ser un texto aleatorio, sin sentido ni pretensión alguna. La conclusión negativa de este examen nos lleva a sostener en este capítulo intermedio una necesaria revisión de hipótesis, conjeturas y planteamientos previos. Esta reconsideración nos conduce a poner en duda la idoneidad de los textos de las lenguas de la Familia Bereber, del Filo Afroasiático, considerados en el capítulo V.

Es el capítulo IX, "Un lenguaje bereber", el que nos sirve de apoyo y soporte en sus datos históricos, arqueológicos, artísticos, lingüísticos y genéticos, para reexaminar el material de la Familia Bereber utilizado con anterioridad, concluyendo en la posibilidad de que nuestra inscripción pertenezca al bereber arcaico, lengua sobre la que se ofrecen las conclusiones lingüístico-filológicas (léxicas, morfológicas, fonéticas, sintácticas y semánticas) capaces de interpretar el texto y situarlo en su contexto propio, en insular amazigh canario.

Finalizamos con el capítulo $\mathrm{X}$, "El significado de la inscripción de la talla (original) de la Virgen de Candelaria" donde recogemos todas las soluciones aportadas hasta hoy a la inscripción, al tiempo que exponemos y damos razón de la ofrecida por nosotros, defendiéndola como la más acorde y posiblemente cercana a la que hace alrededor de seis siglos fue dada a la talla de la Virgen de Candelaria de Canarias. 


\section{METODOLOGÍA}

No vamos a repetir aspectos ya considerados en los apartados previos, sino simplemente resaltar lo que tan importante consideramos en esta investigación, y que creemos se expresa tan acertadamente en la cita del filósofo Karl R. Popper situada al inicio de la investigación.

Creemos que no hubiera sido posible acceder a una solución de la inscripción de la talla sin el estudio interdisciplinar que hemos llevado a cabo. Es más, consideramos que los errores, los equívocos, las frustraciones, las inexactitudes y los desánimos de otros intentos radican en esto mismo. No podemos entender ciertos problemas si no somos capaces de ampliar el radio de visión del mismo. Y esto no es precisamente sencillo. Es más, y esto es incluso más complicado, también creemos que el fraccionamiento de un problema entre diversos especialistas impide un completo y acertado desenlace en la búsqueda de sentido del mismo en algunas ocasiones. Y ello porque de manera tácita e inconsciente gran parte del proceso investigador va guiado por las indicaciones imperceptibles, los filtros y desestimaciones que áreas del conocimiento van marcando para otras ramas, ciencias y disciplinas. Y esto es atemático, difícil de transmitir, y peor aún, difícil de expresar, pero desde la experiencia personal, es sentidamente real y muy habitual. Un problema es percibido según el continente que lo divisa y escruta, y lo que parece confuso o imposible para uno, para otro es obvio o claro, o al menos, menos oscuro y opaco. E incluso, lo que uno considera acertado, otro lo ve como claramente errado, pues no ha considerado aquel otros aspectos y matices que este vislumbra.

Finalmente, y al margen de esta tesis, decir que considero que la mayoría de problemas fundamentales que tenemos como seres humanos son problemas interdisciplinares, y precisan para su solución de una dedicación no solamente fraccionada y distribuida, sino también integral y totalizante. 


\section{Capítulo 1}

\section{Las fuentes documentales textuales de la talla (original) de la Virgen de Candelaria}

\subsection{Objetivo del capítulo}

El texto objeto de nuestro estudio es un texto inscrito en una talla de madera, talla que representa a la Virgen de Candelaria. No obstante, dicha imagen se perdió en un temporal o aluvión que en el año 1826 azotó la isla de Tenerife (islas Canarias). No podemos acceder así a la fuente original de nuestro estudio, al no disponer de la talla. ¿Cuáles eran exactamente esas letras? Este será el objetivo en los próximos dos capítulos: acceder al texto con tanta certeza, autenticidad y exactitud como sea posible. Veremos que lo que inicialmente pareciera simple y directo pronto empezará a tornarse extraño primero y confuso después. Para ello tendremos en cuenta las fuentes documentales textuales o impresas (capítulo actual) así como las no textuales o artísticas (capítulo siguiente) disponibles o no, que son las que recogen de su modo y manera los textos, relatos, crónicas y representaciones, con todas sus variantes y matices, del original. A partir de este material, que posteriormente analizaremos, pretendemos reconstruir el texto primario -tanto como nos sea posible- sobre el que trabajaremos en el resto de la tesis.

Además, este primer capítulo servirá de introducción para situar el problema de esta investigación, para contextualizarlo y ubicarlo. No sólo deseamos acceder al texto escrito en la talla original de Candelaria, sino saber su significado y finalidad. Conocer el sentido de las letras de una talla perdida, que podríamos colocar en el siglo XIV o XV, como cualquier análisis lingüístico y/o criptológico, precisa del contexto. Sin el contexto la solución se hace muchísimo más difícil, si no imposible. Esto nos llevará a preguntarnos por las circunstancias de dicha imagen, su realización, fecha exacta o aproximada de factura, lugar de elaboración, destinatarios y pretensiones y motivos para hacerla y llevarla a una isla en concreto de todo el archipiélago canario, Tenerife, posiblemente aún no conquistada o a punto de ello,... Así, este primer capítulo, sin pretender abarcar lo que en otros se verá suficientemente, servirá para ofrecer una serie de datos primeros, circunstanciales y de contexto, sobre la talla original de la Virgen de Candelaria. 


\subsection{Introducción}

Existen multitud de fuentes documentales que han hablado de la talla original de la Virgen de Candelaria de Tenerife, de sus letras, de su origen y aparición[?][?]. Nuestra pretensión sólo nos llevará a acercarnos a tantas como útiles sean a nuestro propósito, entre ellas, todas las principales, más antiguas y fundamentales, de ahí que siguiendo un orden cronológico -a excepción de dos únicos casos, como ya explicaremos- haremos repaso de las seleccionadas situando al autor y la obra, al tiempo que iremos apuntando y matizando aspectos del relato para mejor entender lo que pudo haber sucedido con vistas a comprender el sentido, significado y alcance de las letras impresas en la imagen.

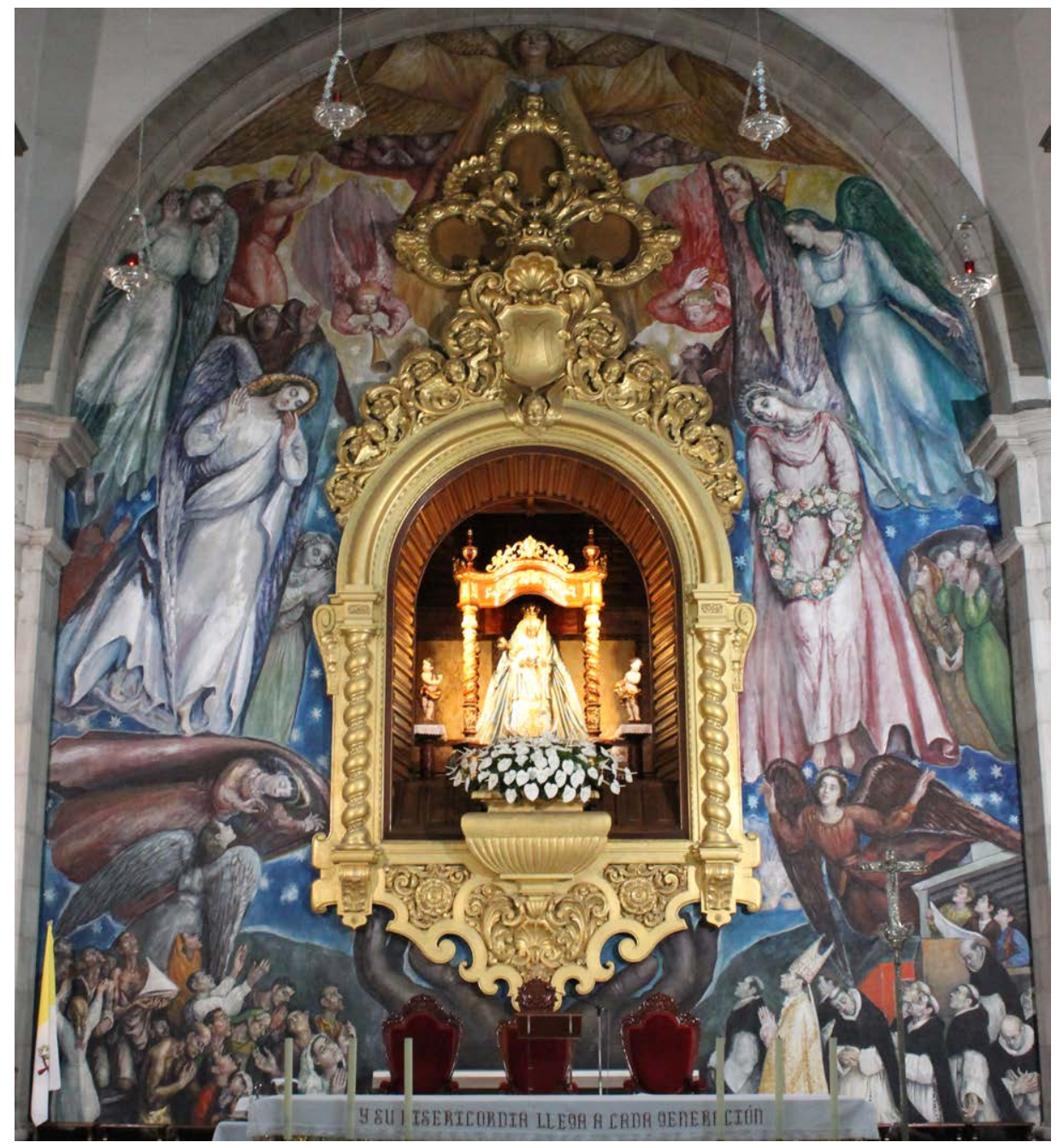

Figura 1.1: Mural del altar mayor de la actual basílica de Nuestra Señora de Candelaria (Tenerife) (Canarias, España) con la nueva talla en el centro y motivos terrenales (plano inferior) y celestiales (plano superior). José Aguiar y García (1895-1976), 1959[?]. (Foto del autor). 


\subsection{Fray Alonso de Espinosa, O.P. y su "Del origen y milagros de la Santa Imagen de nuestra Señora de Candelaria, que apareció en la Isla de Tenerife, con la descripción de esta Isla" (1594)}

Colocamos a este fraile de la Orden de Predicadores (dominicos) en primer lugar, aunque empecemos no respetando el orden cronológico, por ser la primera fuente -y la más detallada y quizás precisa de todas las documentales- que refiere las letras y las acredita. Desde él muchos autores copiarán casi literalmente sus textos y capítulos, por lo que merece cumplidamente la primera mención y la más extensa.

\subsection{Conclusiones}

Tras esta primera toma de contacto con la problemática de nuestra talla y las letras en ella inscritas, ha quedado clara la dificultad de su reconstrucción textual y de todos los acontecimientos que la acompañan, siendo sucesos ocurridos alrededor de seis siglos atrás en el tiempo y con escasa documentación.

Nuestro cometido central y preferente en esta tesis es el acercamiento, en tanto sea posible, al significado, si lo tienen, de las letras de la imagen original, hoy desaparecida, de la Virgen de Candelaria.

Junto a ello están otros aspectos concomitantes como son la datación de la misma, quién la mandó realizar, quién la hizo, el taller y su ubicación, el propósito, el destino de la misma, la posibilidad de que hubiera otro destino distinto al actual y no fuera su principal asignación la isla de Tenerife, ya del archipiélago o fuera de él, el modo como llegó, el momento, la posible relación con la conquista y la evangelización, el motivo de labrarse una talla mariana y no otra imagen religiosa, la razón de la advocación (fiesta de la Candelaria, candela, luz...), etc.

Sin duda, muchas preguntas que no están claras aún hoy en día y que no son objeto de esta tesis y mucho menos de quien esto escribe, incapacitado y escaso en todos los conocimientos que harían falta para realizar, si es que es posible, un acercamiento a estas cuestiones. No obstante, conforme avancemos iremos intentando dar respuesta, hasta donde sea posible, a todas estas preguntas y otras que irán apareciendo, sirviéndonos de diversos autores y especialistas, y ofreceremos algunas opiniones y particulares sugerencias en lo que nosotros creemos fue lo ocurrido. Gran parte de ello se tratará, como venimos diciendo, en el capítulo IV.

Ahora simplemente haremos un breve comentario de la posible datación en base a la documentación aquí expuesta. Y seguidamente, y en base a esta misma aportación documental textual, referiremos las posibles letras perfiladas en la escultura. 


\subsubsection{La posible fecha de la aparición de la talla según las fuentes documentales textuales}

Puede sernos de interés el siguiente gráfico, el cual recoge todo lo expuesto sobre el particular en las obras aquí recogidas, las más antiguas y/o fieles, y sobre las que se basan todas las obras posteriores en los siglos venideros:

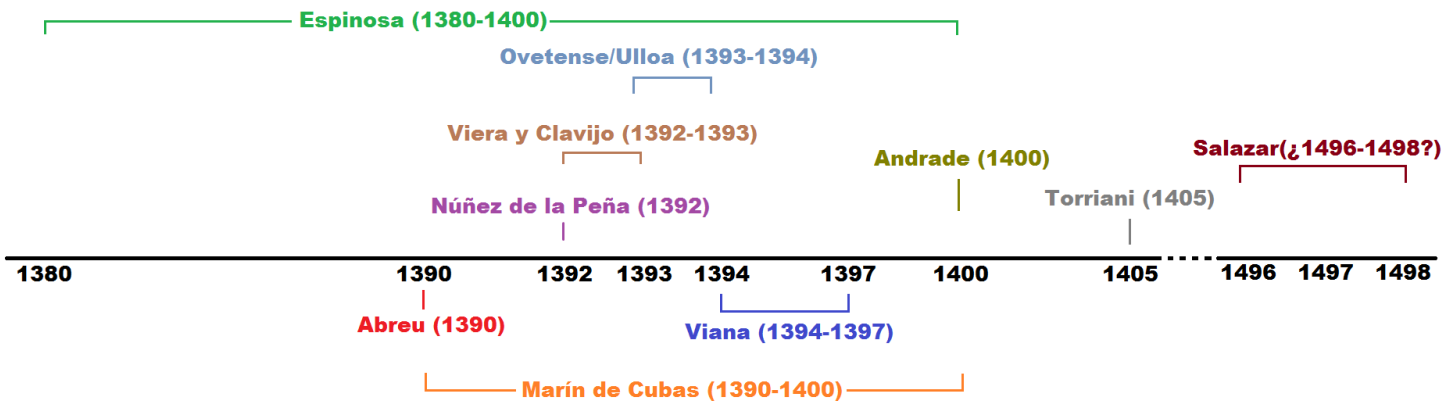

Figura 1.2: Cuadro resumen de fechas de aparición de la talla original de Candelaria según las fuentes documentales textuales presentadas en este capítulo.

Consideramos errónea la data de "Salazar" en la franja 1496-1498, como ya dijimos, demasiado lejana, y que parece confundir los hechos. En todo caso, y en la peor de las lecturas, situamos en el año de 1498 la fecha más tardía de todas las posibles.

El resto de autores ofrece fechas que calculan siempre según el mismo procedimiento, echando atrás años a partir de la conquista de la isla, o de la supuesta evangelización cristiana, que viene a considerarse lo mismo en esta época, año de 1496 o cercanos según cada cual relata, o bien por medio de cómputos a partir del suceso de Antón el guanche. Estas cuentas, y siempre con gran similitud entre los autores, llevan a la horquilla del 1390 al 1405. Espinosa nos aleja hasta el 1380 o algo más si hacemos una lectura laxa de la frase "Más de treinta o cuarenta años estuvo"[?] [en poder de los guanches], "hasta que el año de 1420"[?], lo que lleva al año 1380 o incluso antes[?]. Así, uniendo todo ello, podríamos pensar en la horquilla de 1380 al 1405 como fechas más probables para la datación de la aparición de la imagen en la isla de Tenerife por los pobladores guanches.

No nos decantamos en este momento por un ajuste más fino. Así, nos hemos de ir a fechas más o menos anteriores un siglo a la conquista de la isla de Tenerife (1496). Los autores más antiguos entre los considerados han podido tomar datos y realizar pesquisas e indagaciones de naturales que vivieron los acontecimientos de conquista, los cuales entre los más ancianos pudieron escuchar en su infancia relatos -tan habituales en cualquier pueblo de tradición oral- de la aparición de la talla mariana, acontecimiento trascendental para la población autóctona. Este aspecto vale también como adicional prueba para negar la fecha de 1496-1498 de "Salazar". Por lo tanto, gran coincidencia en las fuentes documentales textuales en este asunto, y un valor "post quem" de 1380 y "ante 
quem" de 1405, lo que supone 25 años de extensión temporal para el acontecimiento. Y esto es lo que podemos ahora decir, a la espera de lo que el análisis histórico-artístico ofrezca en su datación.

\subsubsection{El posible texto inscrito de la talla según las fuentes documentales textuales}

Mostramos a continuación los resultados a la cuestión de cuál era el texto de la talla a partir de los autores y obras que lo recogen y mencionan. Esto supone volver a citar al dominico Alonso de Espinosa, O.P., al franciscano Juan de Abreu Galindo, O.F.M. y su interpretación de Gonzalo Argote de Molina, y en tercer lugar a Juan Núñez de la Peña seguido de la interpretación de Athanasius Kircher, S.I.

Tras ellas ofrecemos lo que sabemos de otras interpretaciones y en lo posible, la base textual sobre la que trabajaron sus autores, a saber, Antonio Salinas, Bartolomé García Ximénez, Carlos Andrés Fernández del Campo, John Campbell, Antonio María Manrique, Alonso Ascanio y Negrín, y finalmente, Fidel Fita Colomé, S.I. y José Hernández Morán.

\section{- Alonso de Espinosa, O.P.}

La relación que ofrece el dominico, recordamos, es la siguiente:

En el cuello de la túnica, el texto "TIEPFSEPMERI".

En el cíngulo o cinturón "NARMPRLMOTARE".

En la bocamanga de la túnica del brazo izquierdo, mano de la candela, "LPVRINENIPEPNEIFANT".

En la parte derecha de la orla del manto "OLM INRANFR IAEBNPFM RFVEN NVINAPIMLIFINVIPI NIPIAN".

En la parte del costado izquierdo de la orla del manto "FVPMIRNA ENVPMTI EPNMPIR VRVIVINRN APVIMFRI PIVNIAN NTRHN".

En la parte inferior de la túnica o fimbria "EAFM IRENINI FMEAREI".

Finalmente, en la parte trasera, no visible frontalmente, en la orla inferior del manto, "NBIMEI ANNEIPERFMIVIFVF".

\section{- Juan de Abreu Galindo, O.F.M.}

Como comentamos al revisar a este autor, corrigiendo los errores de imprenta por medio 
de su solución de acrónimos latinos y uniendo los fragmentos que separa, de clara interpretación, podemos quedarnos con el texto:

(Cuello) "TIEPFSEPMERI".

(Cinturón) "NARMPRLMOTARE".

(Bocamanga lado candela) "LPVR".

(Orla de la saya) "IN[E]NIPEPNEIFANT".

Como vemos, y a pesar de la parcialidad en el texto y la incorrecta ubicación de los dos últimos fragmentos, así como la ausencia de la letra "E" en el último tramo (entre corchetes), coincide casi en su totalidad en lo que ofrece con el texto del dominico Espinosa, más cuando no parece un testigo directo, como ya precisamos. En cuanto a la interpretación, de Gonzalo Argote de Molina, no repetiremos lo ya ofrecido al no tener un mayor interés que el puramente histórico.

\section{- Juan Núñez de la Peña.}

No repetiremos tampoco lo dicho ya y aducido para explicar los errores de linotipista, dejando el texto de este autor y poniendo entre corchetes las letras casi imperceptibles en el texto, y entre paréntesis las letras de Núñez de la Peña junto a la de Espinosa, cercanas en su forma y representación. Así, el texto, cercanísimo de nuevo al de Espinosa, viene a ser:

(Cuello) "TIEPFSEPMERI".

(Cinturón) "(M/N)ARMPRLMOTARE".

(Bocamanga lado candela) "LPVRINENIPEPN[E]IFANT".

(Manto parte derecha) "OLM INRAN(E/F)R IAEBNP(E/F)M RFVEN NVINAPIM(I/L)IFINVIPI NIPIAN".

(Manto parte izquierda) "FVPMIRNA ENVPMTI EPNM(R/P)IR VRVIVINRN APVIMFRI PIVNIAN NTRHN".

(Orla de la saya) "EAFM IRENINI FMEAREI".

(Detrás del manto) "NBIMEI ANNEIPERFMIVIFVF".

- Athanasius Kircher, S.I. 
Ya hemos hablado del intento de dicho sabio jesuita de resolver el enigma de tan conspicuas letras[?], y que hemos recogido en la obra de Jesús Alonso de Andrade, S.I., quien parece ser una fuente de primera mano en el análisis de la talla original, a pesar de las dudas que hemos comentado. Estas son sus anotaciones:

(Cuello) "TIEPESEPMERI".

(Bocamanga lado candela) "EVPMirNa ENuPMTI EPNMPIR VRVIVINRN APVIMERI PIVNIAN NTRHN".

(Manto parte derecha) "OLM INRANFR TAEBNPEM RFVEN NVINAPIMLIFINIPI NIPIAN".

(Orla de la saya) "EAFM IPNINI FMEAREI NBIMEI ANNEIPERFMIVIFVE".

(Cinturón) "NARMPRL[M]OTARE".

(Manto parte izquierda) "LPVRINENIPEPNEIFANT".

\section{- Antonio Salinas.}

A pesar de conocerse, como ya mencionamos, su propia interpretación, como recoge Núñez de la Peña y también Viera y Clavijo[?], no se ha podido de ninguna forma conseguirla desconociendo que alguien pudiera saber su paradero[?], por lo que la damos hoy por hoy por perdida.

\section{- Bartolomé García Ximénez.}

Del obispo Ximénez (1622-1690) y su interpretación también hicimos mención al tratar a Viera y Clavijo, la cual ahora mostramos[?]. Notemos antes que este prelado nunca pretendió resolver el sentido original de las letras, sino ofrecer un significado devocional a las mismas, de ahí que compusiera diversas posibilidades de acrónimos (o cuasi-acrónimos, véase "MIRabilis, NAti,..., NUminis"):

(Cuello) "ETIEPESEPMERI" (="Eccleciae Triumfantis In Excelsis \{Preposita/Praeposita\} Electa Sanctorum Et Patrona Militantis Ecclesiae Romanae \{Infalibilis/Indefectibilis\}").

(Cinturón) "NARMPRLMOTARE" (="Non Ambio Regnorum Magna Palatia Requiro Litora Maris Oceani \{Thenerifensis/Thenerifensia\} Ad Rusticos Edocendos"). Y 10 posibilidades más que ofrece, todas en lengua latina, que luego recogeremos.

(Bocamanga lado candela) "LPVRINENIPEPNEIFANT" (="Lumen Purum Verum Resplendens Inextinguibile Numem Eterni Numinis Invenssientis Predicatoribus 
\{Ecclesiae/Eccleciae\} \{Predicantibus/Praedicantibus\} Nomen Ejus Introite Familian Altissimi Non Tardetis").

(Manto parte derecha) "OLM INRANFR TAEBNPEM REVEN NVINAPIMLIFINIPI NIPIAN" (="Ostendo Lumen Maximum Incipio Novum Regnum Annuntiare Novam Familiam Restaurare Tu Altissime Emitte Benedictionem Novam Paternam Eos Mundans Revela Eis Verba Evangelii Nostri Nottitiam Verbi Incarnati Nati Ate Patre Infinitae \{Mayestatis/Majestatis\} Lumine Intenso Fidei Incende Novo Igne Pectora Ignorantium Non Iam Pater Inimigus Amplius Noceat").

(Manto parte izquierda) "EVPMIRNA ENVPMTI EPNMPIR VRVIVINRN APVIMERI PIVNIAN NTRHN" (="Excelsa Virgo Puerpera MIRabilis NAti Eterni NUminis Potentissima Mater Tuis Influxibus Eminens Patrona Nostra Mater Pietatis Instruens Rusticos Virgo \{Regia/Regina\} Virgo Inmensa Virgo Ineffabilis Nostri Regina Nominis Altissime Purificationis Virgo Immaculata Maria Efundens Reis Indulgentian Pia Impiorum Veniam Nanciscens Insulanis Annuntians Natum Nunquam Thenerifum Relictura Humilibus Nata").

(Orla de la saya) "EAFM IPNINI FMEAREI" (="Ecclesiam Atendite Filii Matrem Ipsius Papam Noscite Infallibilis Numinis Interpretem Filius Meus \{Eum/Eam\} Apposuit Regentem Eam Indefectibilem").

(Detrás del manto) "NBIMEI ANNEIPERFMIVIFVE" (="Nomine Beato Invocabitis Majestatem Eius Inclitam Altissimo Nova Nomine Ejicite Inimicum Patrem Eternum Recognoscite Factorem Mundi In Vitam Ite Futuram Venite Electi").

Junto a estas interpretaciones el obispo daba varias más de las letras del cíngulo, lo que da idea de la versatilidad de la lengua latina, por su forma de construcción declinable, para lograr multitud de posibilidades adecuadas al significado de las letras si son tratadas como siglas o acrónimos. Las consignamos ahora: "Nullum Admissi Reatum Maculae Purissima Regina Libera Mater Omnipotentis Traxi Animan Reatus Exemptam"; "Nominis Atributa Reginae Mariae Purificationis Rosa Tilium Mons Oliva Turris Arca Refugium Ergo"; "Nivariae Aurora Regina Maria Purificationis Regiae Lux Mater Oriens Taumaturga Admirabilis Reparatriis Ethnicorum"; "Nostrum Auxilium Remedium Mater Patrona Refugium Libertas Murus Omega Theotocos Alpha Redemptris Eleemossimaria"; "Nostros Absolve Beatus Maria Potentissima Regina Liberalisima Mater Oramus Te Auxiliare Reis Ejulantibus"; "Non Aspicias Reorum Maculas Placata Respice Liberos Mater Omnipotentis Tuis Auxilis Respiramus Egeni"; "Non Admitas Repugnantia Meae Puritatis Reprime Libidinem Malam Oculos Tentantes Averte Rogabis Exaudiam"; "Non Admittas Retribucionem Magnam Patientiae Respice Laeta Mente Onera Tribulationis Aspice Regnum Aeternum"; "Non Anvieris Retardatione Maternae Prolis Respice Liberum Mariae Omnipotentem Tibi Auxiliabitur Respiciens Eam"; "Nullam Alflixionem Retineas Mulier Proegnans Reminiscere Liberalissimae Mariae Obstrusum Tramitem Aperiet Rogatione Eficaci".

Al margen de las fervorosas y pías soluciones y la creatividad ludo-lingüística de 
los acrónimos latinos, sí tenemos su estructura y disposición de las letras de la imagen mariana, que si bien muy similar a las de Espinosa, no son iguales al completo.

\section{- Carlos Andrés Fernández del Campo.}

También en el año 1702 el sacerdote Carlos Andrés Fernández del Campo (s. XVII-XVIII) dedicó una obra, "Explicación piadosa en castellano de las trece letras, que están en el cíngulo que ciñe la túnica de talla de oro de la muy devota y milagrosa imagen de nuestra Señora de Candelaria en la isla de Tenerife, aplicada a la honra de esta soberana reina y a diferentes accidentes del alma y cuerpo de los que usan de dichos cíngulos", publicada en Sevilla[?][?], si bien dedicándose solamente a tratar de forma piadosa, otra vez de nuevo, como hiciera el obispo Bartolomé, al estudio de las letras del ceñidor, que dice ser trece. El trabajo no tiene ningún interés erudito para lo que nos interesa, si bien no hemos sido capaces de encontrar de ninguna forma una copia de esta obra, aunque al parecer su carácter era simplemente para elevación del fervor[?].

\section{- John Campbell.}

Más peregrina que las deducciones del prelado Bartolomé es la interpretación dada por el erudito escocés John Campbell (1840-1904)[?], que usó de las letras de Espinosa junto con alguna estampa, remitidas por el historiador tinerfeño Juan Bethencourt Alfonso (1847-1913) en el año 1898[?]. No obstante, el texto de su obra[?] muestra algunos errores tipográficos, suponemos que por similitudes entre las letras o por mezclar diferentes fuentes (texto e imagen), que recogemos entre paréntesis $\left(1^{\circ}\right.$ la de Campbell y $2^{\circ}$ la de Espinosa), así como una omisión (entre corchetes). La interpretación dada fue un origen ibero o etrusco, y afirmando que la estatua era en realidad la diosa pagana Menera[?]. Para él esta lengua ibero o etrusca hundía sus raíces filológicas en el vasco arcaico, de ahí que a partir de voces vascuences realizara una aproximación fonético-silábica a lo que él creía era ibero-insular[?][?]. Juan Bethencourt Alfonso, siguiendo estos datos, apunta equivocadamente un significado en las letras de la talla bajo influencias religiosas etruscas, romanas y griegas, diciendo que la diosa es Menera, diosa ibera insular, que liga al pueblo etrusco y al siglo I a. C. Yerra también queriendo ver en las cruces que trocean el texto un símbolo de religiosidad de Visnú, la esvástica. Cita además a Marcelino Menéndez Pelayo (1856-1912), para quien también es claro su significado religioso y de buen agüero[?][?][?]. Como hoy es claro, toda esta apreciación, deducción y conclusiones son un absurdo sin base alguna, afirmando incluso que los caracteres eran etruscos pero pareciendo latinos (sic). Quizás esta explicación se deba a que Juan Bethencourt Alfonso además de los letreros de la talla le remitió diferentes inscripciones líbico-bereberes de las islas, ofreciendo una amalgama de conciliarismo y concordancia que le alejó de una sopesada respuesta[?]. Esta fue su respuesta[?]:

(Cuello) "TIEPFSEPMERI" (="ko i en tu po no en tu me ne ra au $\rightarrow$ koi entu pono entu Menera au. // Deseo oir pesar oir Menera esto $\rightarrow$ Que la (diosa) Menera oiga mi plegaria, atienda mi pena"). 
(Cinturón) "(M/N)ARMPRLMOTARE" (="mi ra er mi to ri se me ma gu re er en $\rightarrow$ mira erimi etorri seme etna gure erren. // Espectáculo causa presento venga hijo dar nuestra compasión $\rightarrow$ Ante la causa que nos obliga a presentar nuestro hijo, compadécete de nosotros").

(Bocamanga lado candela) "LPVRINENIPEPN[E]IFANT" (="so to be ri u ga ne ka ai ta en tu ka i ba ra ka ko $\rightarrow$ Sotoberri uga neke aita entu Kai barka ka. // Sotoberri madre cansado padre oir Caius perdonando por $\rightarrow$ La madre Sotoberri y el padre afligido ruegan ser perdonados por medio de Caius").

(Manto parte derecha) "OLM INRAN(E/F)R IAEBNP(E/F)M RFVEN NVINAPIMLIFINVIPI NIPIAN" (="ma sa mi u ga ra er ka an re au ra ne la ka tu ne mi ar ba be ne ka ga be au ka ri di o me te ba hi ga be ai ta au ka i di o er ka $\rightarrow$ etnaitsa imiy uga ra erruki anre aur ne lekatu ne imi Arba be neke gabe au ekarri dio ematu bahi-gabe aita au Kai dio erruki. // Ofrenda presentar madre a compasiva Señora niño placer colocar Arba debajo disgustado. Pérdida niño soportar el calma promesa despojado padre este Caius él compadece $\rightarrow$ Como madre hago con placer la ofrenda del niño a la compasiva Señora, si redime la pena de Arba. Hace la madre ofrenda del niño a la compasiva Señora para complacer (dar ánimo) al apenado Arba, cansado de sufrir. Que él calme a este padre despojado de la ofrenda que él se compadezca de Caius").

(Manto parte izquierda) "FVPMIRNA ENVPMTI EPNM(R/P)IR VRVIVINRN APVIM(E/F)RI PIVNIAN NTRHN" (="pa be tu mi au ra ka ri ni ga be tu mi koi en tu ka mi ra au ra be re be ha be ha ka er ka ar tu be ha me ne ra au do i be kai er ka ga go ra te ka $\rightarrow$ pabetu imi aur ekarri ni gabetu imi koi entuka mira aur bere beha behaka erruki artu beha Menera au doi be Kai erruki gogoratu ka. // Ayudar colocar niño llorar yo arrebatado sitio deseo en oyendo mira niño suyo contemplar en contemplando piedad. Tomar mirada Menera esta justicia bajo Caius compasiva recordando por $\rightarrow$ Sobreponiéndose a su dolor ayuda a colocar el niño llevándolo arrebatadamente al sitio, y al oír sus lamentos mira a su propio hijo y lo contempla con piedad. ¡Dirige una mirada, tú, Menera, ten compasión por la memoria de Caius!").

(Orla de la saya) "EAFM IRENINI FMEAREI" (="ni ar ba mi au ra ne ka i ka i ba me ne ra er en ai $\rightarrow$ ni Arba imi aur ne Kai, ba Menera errunat. // Yo Arba presento niño a Caius si Menera se compadece $\rightarrow$ Yo Arba ofrezco este niño Caius si Menera se compadece aceptado a Caius").

(Detrás del manto) "NBIMEI ANNEIPERFMIVIFVF" (="ka ol au mi ni o er ka ka ni o du en ar ba mi o bi ne au pa be ba $\rightarrow$ zchol au imi nio erruki egi nio duen Arba imi obi ne au pabe ba. // Cuidado este lugar yo a él piedad hago yo a él es quien Arba coloca tumba a este ayuda lugar $\rightarrow$ Yo dedico esta memoria a él; yo tengo piedad de él. Soy yo, Arba, quien puso en la tumba este santuario").

Para nuestro interés, podemos ver cómo se le remitió un texto similar al del fraile dominico, aunque finalmente usó otro distinto con ligeras variantes o incorrecciones de 
imprenta o bajo influjo de otro distinto en la estampa remitida. En cuanto a la solución de Campbell, muy insuficiente e inesperada, sólo decir que nos sorprende el grado de lejanía y ubicación con la arqueología, la etnografía y la lingüística del archipiélago[?].

\section{- Antonio María Manrique.}

En el año 1898 se da otro intento, del que apenas se publicó nada más que una primera parte en el periódico "La Opinión", el 27 de diciembre de dicho año, si bien la fecha el día 14 del mismo mes, por parte del investigador y erudito canario Antonio María Manrique (1837-1907)[?]. Este estudioso hará la suposición de que los textos han de tener algún significado religioso ligado a la propia Virgen María, de ahí que sugiera que "ese letrero que figura en el cuello de la Virgen, precisamente en donde se suele colocar un nombre, un retrato, en donde de una cadena o un cordón penden algunas insignias de honor, ese letrero, digo, que se relaciona con el individuo que lo lleva u ostenta, y él me ha hecho sospechar que ha de hacer alusión al nombre de la imagen. [...] Esa inscripción, repito, da la idea de haber sido reproducida una frase semita, con caracteres latinos, escribiéndose de izquierda a derecha, y no al contrario, como lo requieren los caracteres arábigos, etc., y si no pecase de atrevido, yo aseguraría desde luego que esas letras lo que quieren decir, es lo que entre nosotros significa MARIA DE GRACIA LLENA". Seguidamente muestra la dificultad de atreverse con el resto, y así dice: "En cuanto a las demás inscripciones, no es posible aventurarse a hacer una afirmación que llegue a ser comprobada; pero se me figura notar cierta analogía entre su interpretación y las palabras de una epistola del Apóstol S. Pablo". A continuación y con este dato paulino intenta resolver las letras del cíngulo dando el sentido de que "tal vez pudiera leerse algo parecido a esto: 'Un Dios y padre común'. Hechas estas revelaciones, corresponde ahora a las personas entendidas admitirlas o desecharlas según su criterio, debiendo advertir desde ahora que la reproducción de las voces semíticas ha sido pésima, habiendo resultado lo mismo que sucediera hoy al querer representar vocablos arábigos prescindiendo de los caracteres propios del respectivo alfabeto. De ahí, seguramente la idea de una disparatada ortografía o de caprichosos adornos, cuando tratamos de leer las inscripciones de Candelaria, sin advertir que se trata de una escritura aljamiada".

No conocemos con certeza las letras y textos que consideraba más dignas de crédito, si bien se desprende del cuerpo del artículo de prensa que descarta a todos los autores y se queda con el dominico Espinosa: "Uno de los que con mayor interés se ocupó de nuestra Candelaria fué el P. Fr. Alonso de Espinosa. El, que examinó con detención la imagen, hace de la misma una descripción completa, sin omitir aquellos misteriosos letreros de al Virgen. [...] tal cual describen esta imagen nuestros historiadores, muy especialmente el citado Fr. Alonso de Espinosa".

Tal y como podemos ver, estamos en una época donde es fuerte la creencia de que el letrero sea de origen semita, buscando sentidos cristianos e incluso bíblicos a los incomprensibles letreros, escritos con grafemas latinos. 
- Alonso Ascanio y Negrín.

En la misma línea que la anterior de John Campbell tenemos la interpretación dada en el año 1899 por este erudito de La Orotava (Tenerife), Alonso Ascanio y Negrín (1855-1936), aplicándose al descifrado de las letras según el modelo textual de Espinosa, dando la singular opinión que ahora sigue[?][?]:

(Cuello) "ME SOBRA O GAJE".

(Cinturón) "EVIIOJ DE NOVIA".

(Bocamanga lado candela) "COMO H (hermana) JEMELA ONA HAZES".

(Manto parte derecha) "OJJEMPUJA LA PEANNE LO EVA DE SINTO E DICE DES BOCEHIAYD".

(Manto parte izquierda) "ET OJZILA EN S. FIJA OJME O POLEL AL OHRILED DOE HARDA Y EMPLEE".

(Orla de la saya) "AZZI D’OY ME H. FAGAS LA B".

(Detrás del manto) "LA FIXE SINESIVJ ZEA MCCXLIX".

Una singular traducción con pseudo-español, fingido portugués y simulado italiano donde lo verdaderamente enigmático es el descubrir cómo del texto origen pudo llegar a esta interpretación, alcanzando incluso, como podemos ver en el resultado de la parte trasera del manto, a afirmar que la talla la hizo un tal Sinesiuj Zea en el año 1249.

\section{- Fidel Fita Colomé, S.I.}

José Rodríguez Moure (1855-1936) envió al padre Fita (1845-1918) en el año 1912, presidente de la Academia de Historia, fotografías facsímil de la antigua imagen y de las medallas primeras, de las que hablaremos en el siguiente capítulo. Deseaba saber si la imagen podía ser de origen fenicio, o al menos pagana, o era una Virgen cristiana. Ante ello el académico respondió ser claramente una figura cristiana. También se le pedía su opinión en cuanto a las letras, ante lo que contestó adherirse a lo que ya había dicho el padre Andrade. Añadía que el tipo de letras del medallón eran del mismo estilo que los plomos estilo 85 granadino, del siglo XV en su segunda mitad, como los del cinturón o pretina de la talla mariana, atreviéndose a decir que las letras del cuello ("ETIEPESEPMERI") era una reordenación del texto "Sepi et eripe me" ("protégeme y rescátame"), aludiendo a la invocación de la letanía "Turris ebúrnea" ("torre de marfil") en base al Cantar de los Cantares 8, 4[?] (más correcto sería decir Cant 4, 4)[?] o Isaías 5, 2, que dice "Et sepivit eam, [...] et aedificavit turrim" ("Y la cavó (la viña) [...] y construyó una torre")[?][?][?]. 
Queda claro que las letras de las que hace uso son las del obispo Bartolomé García Ximénez. Por otro lado, muy forzada nos parece la transposición de las letras del cuello así como llevar su semántica hacia los dos versículos del Antiguo Testamento referidos, muestra de la dificultad para los mayores estudiosos y especialistas del mismo siglo XX.

\section{- José Hernández Morán.}

El historiador José Hernández Morán (1922- ) en el año 1957 seguía el texto de Athanasius Kircher, S.I., dando algunas soluciones a varias de las inscripciones[?]:

(Cuello) Aquí ofrecía dos posibilidades, por un lado, la sub-partición "TI-E-PE-SEP-MERI" (="Tú eres por siempre María"), desde la variante de Kircher, o bien, la forma más forzada "TI-ERES-EP-MERI" (="Tú eres espejo de madre"), con lo que se quiere mostrar en línea semántica con la versión "Tipus Matris" ("Imagen de la Madre") del jesuita.

(Bocamanga lado candela) "LPVRINENIPEPNEIFANT", que puntúa o subdivide como "L-PVRI-MERI-PEP-NE-IFANT" (="La purificación de la Madre después de nacido el Infante"), recogiendo el sentido que en otro lugar, el manto en su parte izquierda, hiciera de nuevo el mismo Kircher al ofrecer la solución "Purificatio et Praesentatio Infantis" ("La Purificacion, y Presentacion del Infante").

(Detrás del manto) "ANNEIPERFMIVIFVE", que subdivide "ANNEI-PER-F-MIVI-FVE", sobre la que dice ser su significado "Año para hacerlo 1401 fue (tomando como una incorrección, propia de la época, el cifrado romano de la fecha)".

Una interesante propuesta por los acercamientos de los fragmentos a cuasi-palabras latinas o españolas, a veces simples iniciales, como en "E" ("eres"), "L" ("La") o "F" ("fecit") ("hizo"), otras veces dos letras, como en "PE" ("per") ("por") o "EP" ("espejo"), a veces palabras casi completas como "PVRI" ("purificación") o "IFANT" ("infante"), o incluso enteras, como "FVE" ("fue"), sin demasiado orden y principio rector constructivo, con mezcla de lengua latina e hispana, con palabras no del todo bien escritas, y el llamativo "1401" como "M-IV-?-I", lo que tampoco es una fecha esperada, pues ni es 1390 ni 1400, o alguna de las anteriormente mencionadas. Una solución que además es incompleta al no darse el resto de fragmentos de la indumentaria, quizás por no poderse obtener otras similares propuestas a estas.

¿Qué decir de todo lo expuesto en este apartado? Que lo que parecía simple en su inicio, de sencillo y evidente tiene poco. Más bien, todo lo contrario. Encontramos diferencias y divergencias, si bien en general pocas y algunas explicables por parecido en la grafía de los grafemas. Pero nos parece sorprendente encontrar tantas disonancias y disparidades. No queda todo dicho, hemos de ver lo que el aporte de fuentes documentales 
artísticas ofrece, y cómo decantan en su conjunto el texto, si no lo complican todavía más, como intuimos.

Por ahora, mostremos en una tabla lo que a partir del material analizado podemos decir de cuál sea el texto origen. Para ello recogeremos sombreado en color rojo las letras de las que tenemos una variante, al menos, en algunas de las fuentes; y en color azul si se diera una ausencia en alguna, al menos, de ellas (quitando a Abreu, que no ofrece la solución completa). Para el resto, que son las de total coincidencia entre las fuentes, las letras aparecerán sin coloración.

\begin{tabular}{|c|c|c|c|c|c|c|c|c|c|c|c|c|c|c|c|c|c|c|c|c|c|c|c|c|c|c|c|c|c|c|c|c|c|c|c|c|c|}
\hline ALONSO DE ESPINOSA & T & 1 & $\mathrm{E}$ & $\mathbf{P}$ & & \begin{tabular}{|l|l|l|l}
$S$ & $E$
\end{tabular} & & $\mathbf{M}$ & \begin{tabular}{|l|l}
$E$ & $R$ \\
\end{tabular} & & + & & \begin{tabular}{|l|l|l|l}
$A$ & $R$ \\
\end{tabular} & \begin{tabular}{|l|l|l|l}
$M$ & $P$ \\
\end{tabular} & $\mathbf{R}$ & & M & 0 & $\begin{array}{ll}\mathrm{T} & \mathrm{A} \\
\end{array}$ & $\mathbf{R}$ & & & & $\mathrm{v}$ & & $N$ & & $\begin{array}{ll}N & 1 \\
\end{array}$ & & E & \begin{tabular}{l|l}
$\mathbf{P}$ & $\mathrm{N}$ \\
\end{tabular} & \begin{tabular}{|l|l|l|}
$N E$ & \\
\end{tabular} & $1 \mathrm{~F}$ & & \begin{tabular}{|l|l|l|}
$N$ & $T$ \\
\end{tabular} & & \\
\hline JUAN DE ABREU GALINDO & T & 1 & $E$ & $\mathrm{P}$ & & \begin{tabular}{|l|l|l|l} 
& $E$ \\
\end{tabular} & 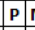 & M & $\begin{array}{ll}E & R \\
\end{array}$ & is & + & & $\begin{array}{lll}A & R \\
\end{array}$ & \begin{tabular}{|l|l|l|l}
$M$ & $P$ \\
\end{tabular} & $\begin{array}{ll} \\
\end{array}$ & & M & 0 & & $\mathrm{R}$ & & + & & \begin{tabular}{l|l}
$\mathrm{V}$ & $\mathrm{r}$ \\
$\mathrm{c}$
\end{tabular} & & $\mathrm{N}$ & & N I & & & & & & & \begin{tabular}{|l|l|l|l|l|l|l}
$N$ & $T$ \\
\end{tabular} & + & \\
\hline Z DE LA PEÑA & T & I & E & $\mathbf{P}$ & & & & M & $\begin{array}{ll}E & R \\
\end{array}$ & & & & \begin{tabular}{|l|l|l|l|l|l|l|l}
$A$ & $R$ \\
\end{tabular} & \begin{tabular}{l|l}
$\mathrm{P}$ & $\mathrm{P}$ \\
\end{tabular} & \begin{tabular}{|l|l|l|}
$T$ \\
\end{tabular} & & M & 0 & $\mathrm{~T} A$ & $\mathrm{R}$ & & + & & $\mathrm{V} F$ & \begin{tabular}{l|l|l|l|l|l|l|l|l}
$R$ & 1 \\
\end{tabular} & $\mathrm{~N}$ & & $N 1$ & & & \begin{tabular}{l|l}
$P$ & $N$ \\
\end{tabular} & & \begin{tabular}{l|l}
$1 \mathrm{~F}$ \\
$\mathrm{~T}$
\end{tabular} & & \begin{tabular}{|l|l|l}
$N$ & $T$ \\
\end{tabular} & + & \\
\hline THANAS & T & 1 & $\mathrm{E}$ & $\mathbf{p}$ & & \begin{tabular}{|l|l|l|l}
$S$ & $E$ \\
\end{tabular} & & M & $\begin{array}{ll}E & R \\
\end{array}$ & $\mathrm{R}$ & + & & \begin{tabular}{|l|l|l|l|l|l|l|l} 
& $R$ \\
\end{tabular} & \begin{tabular}{|l|l|l}
$M$ & $P$ \\
\end{tabular} & $\mathrm{R}$ & $\mathrm{L}$ & & $\mathrm{o}$ & TA $A$ & $\mathrm{R}$ & & + & & 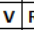 & \begin{tabular}{l|l|l|l|l|l|l|l|l}
$R$ & 1 \\
\end{tabular} & $\mathrm{~N}$ & E & \begin{tabular}{l|lll}
$\mathrm{N}$ & $\mathrm{I}$ \\
\end{tabular} & & E & \begin{tabular}{l|l}
$P$ & $N$ \\
\end{tabular} & N & I $\mathrm{F}$ & & \begin{tabular}{|l|l|l}
$N$ & $T$ \\
\end{tabular} & + & \\
\hline BARTOLOMÉ GARCÍA XIMÉNEZ & \begin{tabular}{|l|l|l} 
E & T \\
\end{tabular} & 1 & $\mathrm{E}$ & $\mathbf{P}$ & $s$ & \begin{tabular}{|l|l|l|l|l}
$S$ & \\
\end{tabular} & & $\mathrm{M}$ & $\begin{array}{ll}E & R \\
\end{array}$ & & + & & \begin{tabular}{|l|l|l|l|l|l}
$A$ & $R$ \\
\end{tabular} & \begin{tabular}{|l|l}
$\mathrm{P}$ & $\mathrm{P}$ \\
\end{tabular} & \begin{tabular}{|l|l|}
$f$ & $R$ \\
\end{tabular} & & M & 0 & $\mathrm{~T} A$ & $\mathrm{R}$ & & + & & \begin{tabular}{l|l}
$\mathrm{V}$ & $\mathrm{F}$ \\
$\mathrm{n}$
\end{tabular} & \begin{tabular}{l|l|l|l|l|l|l|l}
$R$ & I \\
\end{tabular} & $\mathrm{N}$ & E & \begin{tabular}{l|l|l|l}
$N$ & 1 \\
\end{tabular} & & $E$ & \begin{tabular}{l|l}
$\mathrm{P}$ & $\mathrm{N}$ \\
\end{tabular} & & \begin{tabular}{l|l} 
& $F$ \\
\end{tabular} & & \begin{tabular}{|l|l|l}
$N$ & $T$ \\
\end{tabular} & + & \\
\hline JOHN CAMPBELL & & & $\mathrm{E}$ & $\mathbf{p}$ & & & & M & & & + & & $\mathrm{A} \mid \mathrm{R}$ & $\mathrm{M} / \mathrm{P}$ & $\begin{array}{lll}P & R \\
\end{array}$ & $\mathrm{~L}$ & $\mathrm{M}$ & & TA & $\mathrm{R}$ & & $+\mathrm{L}$ & & \begin{tabular}{l|l}
$\mathrm{V}$ & $\mathrm{B}$ \\
\end{tabular} & & $\mathrm{N}$ & EN & $\begin{array}{lll}\mathrm{N} & \mathrm{I} \\
\end{array}$ & & & & & I] $\mathrm{F}$ & & \begin{tabular}{|l|l|l} 
& $T$ \\
\end{tabular} & + & \\
\hline ALONSO DE ESPINOSA & \begin{tabular}{|l|l}
$\mathrm{O}$ & $\mathrm{L}$ \\
\end{tabular} & $\mathrm{M}$ & + & $1 \mathrm{n}$ & \begin{tabular}{l|l}
$\mathrm{N}$ & $\mathrm{R}$ \\
\end{tabular} & \begin{tabular}{l|l}
$R$ & $A$ \\
\end{tabular} & $\mathrm{~N}$ & & $\mathrm{R}+$ & & A & E & \begin{tabular}{l|l} 
\\
\end{tabular} & $\mathbf{P}$ & M & + & $\mathrm{R}$ & & $\begin{array}{ll}\mathrm{V} & \mathrm{E} \\
\end{array}$ & $N$ & & $\mathrm{~N} V \mathrm{~V}$ & 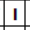 & $\mathbf{N}$ & A $\mathbf{P}$ & 1 & M & 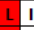 & $\begin{array}{ll} & F \\
\end{array}$ & 1 & \begin{tabular}{l|l}
$\mathrm{N}$ & $\mathrm{v}$ \\
\end{tabular} & \begin{tabular}{l|l}
$v$ & 1 \\
\end{tabular} & \begin{tabular}{l|l}
$\mathbf{P}$ & $\mathrm{I}$ \\
\end{tabular} & 1] & \begin{tabular}{|l|l|l|}
$N$ & $I$ \\
\end{tabular} & \begin{tabular}{|l|l}
$\mathbf{P}$ & $\mathbf{r}$ \\
\end{tabular} & \begin{tabular}{l|l|l|} 
& $A$ & $N$
\end{tabular} \\
\hline \multicolumn{38}{|l|}{ JUAN DE ABREU GALINDO } \\
\hline AN I & $\begin{array}{ll}0 & L \\
\end{array}$ & M & + & 1 & $\mathrm{R}$ & \begin{tabular}{l|l}
$R$ & $A$ \\
\end{tabular} & $\mathrm{~N}$ & & $\mathrm{R}+\mathrm{+}$ & & A & E & $\begin{array}{lll}\mathrm{N} \\
\end{array}$ & $\mathrm{p}$ & M & + & $\mathrm{R}$ & & $\begin{array}{ll}\mathrm{V} \\
\mathrm{E}\end{array}$ & $\mathrm{N}$ & & $\mathrm{N} V \mathrm{~V}$ & & $\mathrm{~N}$ & $A \mid P$ & & M & & \begin{tabular}{|l|l|} 
& $F$ \\
\end{tabular} & & \begin{tabular}{l|l}
$\mathrm{N}$ & $\mathrm{V}$ \\
\end{tabular} & & \begin{tabular}{l|l}
$\mathbf{P}$ & $\mathrm{I}$ \\
\end{tabular} & & \begin{tabular}{|l|l|l}
$N$ & I \\
\end{tabular} & \begin{tabular}{|l|l}
$\mathbf{P}$ & $\mathbf{1}$ \\
\end{tabular} & \begin{tabular}{|l|l|}
$A$ & $N$ \\
\end{tabular} \\
\hline $\mathrm{ATH} /$ & $\begin{array}{ll}0 & L \\
\end{array}$ & $\mathrm{M}$ & it & $1 \mathrm{n}$ & \begin{tabular}{l|l}
$\mathrm{N}$ & $\mathrm{R}$ \\
\end{tabular} & \begin{tabular}{l|l}
$R$ & $A$ \\
\end{tabular} & $\mathrm{~N}$ & & $\mathrm{R}+\mathrm{+}$ & & A & E & $\begin{array}{lll}\mathrm{N} \\
\end{array}$ & $\mathrm{p}$ & M & + & $\mathrm{R}$ & & $\begin{array}{ll}\mathrm{V} \\
\mathrm{E}\end{array}$ & $N$ & & $\mathrm{~N} / \mathrm{V}$ & 1 & $\mathrm{~N}$ & $A \mid P$ & & M & & \begin{tabular}{l|l}
$\mathrm{F}$ \\
\end{tabular} & & $\mathrm{N}$ & & \begin{tabular}{l|l}
$\mathbf{P}$ & $\mathrm{I}$ \\
\end{tabular} & & \begin{tabular}{|l|l|l}
$N$ & I \\
\end{tabular} & $\mathbf{P}$ & \begin{tabular}{l|l|l|} 
& $A$ & $N$
\end{tabular} \\
\hline XIMÉNEZ & $\begin{array}{ll}0 & L \\
\end{array}$ & M & it & $1 \mathrm{R}$ & \begin{tabular}{l|l}
$\mathrm{N}$ & $\mathrm{R}$ \\
\end{tabular} & \begin{tabular}{l|l}
$R$ & $A$ \\
\end{tabular} & $\mathrm{~N}$ & & $\mathrm{R}+\mathrm{+}$ & & A & E & $\begin{array}{lll} \\
\mathrm{N}\end{array}$ & $\mathrm{p}$ & M & + & $\mathrm{R}$ & & $\begin{array}{ll}\mathrm{V} \\
\mathrm{V}\end{array}$ & $N$ & & $\mathrm{~N} V \mathrm{~V}$ & 1 & $\mathrm{~N}$ & A $P$ & 1 & M & & \begin{tabular}{|l|l|} 
& $F$ \\
\end{tabular} & & $\mathrm{~N}$ & $1 \mathrm{P}$ & \begin{tabular}{l|l}
$\mathbf{P}$ & $\mathrm{I}$ \\
\end{tabular} & & \begin{tabular}{|l|l|l}
$\mathrm{N}$ & $\mathrm{I}$ \\
\end{tabular} & $\mathbf{P}$ & \begin{tabular}{l|l|l|} 
& $A$ & $N$
\end{tabular} \\
\hline JOHN CAMPBELL & $0 \mathrm{~L}$ & $\mathrm{M}$ & + & $1 \mathrm{n}$ & & $\begin{array}{lll}\mathrm{R} & \mathrm{A} \\
\end{array}$ & $\mathrm{N}$ & & $\mathrm{R}]+$ & & A & E & $B$ & $\mathbf{p}$ & $\mathrm{M}$ & + & $R$ & & $\mathrm{~V} \mid \mathrm{E}$ & $\mathrm{N}$ & & $\mathrm{N} \mid \mathrm{V}$ & 1 & $\mathbf{N}$ & $\mathbf{A} \mathbf{P}$ & 1 & M & & I. $\mathrm{F}$ & & $\mathrm{N} / \mathrm{V}$ & & & & \begin{tabular}{|l|l|l|l|} 
& $I$ \\
\end{tabular} & $\mathbf{p}$ & \begin{tabular}{l|l|}
$\mathbf{A}$ & $\mathbf{N}|+|$ \\
\end{tabular} \\
\hline ALONSO DE ESPINOSA & $\mathrm{v}$ & $\mathbf{p}$ & M & 1 & \begin{tabular}{l|l}
$\mathrm{R}$ & $\mathrm{N}$ \\
\end{tabular} & \begin{tabular}{|l|l|l|l|}
$N$ & $A$
\end{tabular} & & E & \begin{tabular}{l|l}
$\mathrm{N}$ & $\mathrm{V}$ \\
\end{tabular} & & M & $\mathrm{T}$ & $1+$ & \begin{tabular}{|l|l}
$E$ & $P$ \\
\end{tabular} & \begin{tabular}{l|l}
$\mathrm{P}$ & $\mathrm{N}$ \\
\end{tabular} & M & & it & R + & $\mathrm{v}$ & $\mathrm{R}$ & \begin{tabular}{l|l}
$\mathrm{V}$ & $\mathrm{I}$ \\
\end{tabular} & $\mathrm{v}$ & \begin{tabular}{|l|l}
1 & $n$ \\
\end{tabular} & \begin{tabular}{|l|l|l|l|l|}
$N$ & $R$ \\
\end{tabular} & $\mathrm{~N}$ & + & \begin{tabular}{l|l}
$A$ & $P$ \\
\end{tabular} & \begin{tabular}{l|l}
$\mathrm{P}$ & $\mathbf{v}$ \\
\end{tabular} & & M & 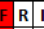 & $1+$ & & \begin{tabular}{l|l}
$\mathrm{V}$ \\
$\mathrm{T}$
\end{tabular} & $\mathrm{N}$ & \begin{tabular}{|l|l|l|} 
& $A$ & $N$
\end{tabular} \\
\hline \multicolumn{38}{|l|}{ JUAN DE ABREU GALINDO } \\
\hline JUA & $\mathrm{v}$ & $\mathbf{P}$ & M & & & $\begin{array}{lll}\mathrm{N} A \mathrm{~A} \\
\mathrm{~N}\end{array}$ & & E & $\mathrm{N} \mid \mathrm{V}$ & & $\mathrm{M}$ & $\mathrm{T}$ & $1+$ & \begin{tabular}{|l|l|l}
$E$ & $P$ \\
\end{tabular} & $\begin{array}{ll}\mathrm{P} & \mathrm{N} \\
\end{array}$ & $M$ & & 1 & $R+$ & $v$ & & v 1 & v & 10 & & $\mathrm{~N}$ & + & & p v $v$ & & M & $R I$ & $1+$ & & I V & $\mathrm{N}$ & I A $N+$ \\
\hline ATHA & $\mathrm{v}$ & $\mathrm{p}$ & M & 1 & & $\begin{array}{lll}N & A \\
\end{array}$ & & E & $\mathrm{N} \mid \mathrm{V}$ & & M & $\mathrm{T}$ & $1+$ & \begin{tabular}{|l|l}
$E$ & $P$ \\
\end{tabular} & $\mathrm{~N}$ & $M$ & & 1 & R + & $\mathrm{v}$ & & \begin{tabular}{l|l}
$\mathrm{v}$ & $\mathrm{I}$ \\
\end{tabular} & $\mathrm{v}$ & \begin{tabular}{l|l}
1 & 1 \\
\end{tabular} & \begin{tabular}{|l|l|l|l|l|l|l}
$N$ & $R$ \\
\end{tabular} & $\mathrm{~N}$ & + & \begin{tabular}{l|l}
$A$ & $P$ \\
\end{tabular} & $\begin{array}{lll}p & v \\
\end{array}$ & & M & $\mathrm{R} \mid \mathrm{I}$ & $1+$ & & \begin{tabular}{l|l}
$\mathrm{I}$ & $\mathrm{V}$ \\
\end{tabular} & $\mathrm{N}$ & \begin{tabular}{|l|l|}
$\mathrm{A}$ & $\mathrm{N}$ \\
\end{tabular} \\
\hline BARTOLOMÉ GARCÍA XIMÉNEZ & $\mathrm{v}$ & $\mathrm{P}$ & M & 1 & & $\mathrm{~N} A$ & & E & $\mathrm{N} \mid \mathrm{V}$ & & M & $\mathrm{T}$ & $1+$ & \begin{tabular}{|l|l}
$E$ & $P$ \\
\end{tabular} & \begin{tabular}{l|l}
$\mathrm{P}$ & $\mathrm{N}$ \\
\end{tabular} & $M$ & & 1 & R + & $v$ & & \begin{tabular}{l|l}
$\mathrm{v}$ & $\mathrm{I}$ \\
\end{tabular} & $\mathrm{v}$ & \begin{tabular}{l|l}
1 & $n$ \\
\end{tabular} & $\begin{array}{lll}N & R \\
\end{array}$ & $\mathrm{~N}$ & + & \begin{tabular}{l|ll}
$A$ & $P$ \\
\end{tabular} & \begin{tabular}{l|l}
$\mathbf{p}$ & $\mathbf{v}$ \\
\end{tabular} & & M & RI & $1+$ & & \begin{tabular}{l|l}
$\mathrm{I}$ & $\mathrm{V}$ \\
\end{tabular} & $\mathrm{N}$ & $|A| n \mid$ \\
\hline OHN CAMPBELL & $\mathbf{v}$ & P & M & 1 & & $\begin{array}{llll}N & A \\
\end{array}$ & & E & $\mathrm{N} / \mathrm{V}$ & & M & $\mathrm{T}$ & 1] +1 & \begin{tabular}{|l|l}
$E$ & $P$ \\
\end{tabular} & \begin{tabular}{l|l} 
& $\mathbf{N}$ \\
\end{tabular} & $\mathrm{M}$ & & 1] & R]+ & $\mathrm{v}$ & & \begin{tabular}{l|l}
$\mathrm{v}$ & $\mathrm{I}$ \\
\end{tabular} & v & \begin{tabular}{|l|l} 
& 1 \\
\end{tabular} & $\begin{array}{lll} & R \\
\end{array}$ & $\mathrm{~N}$ & +1 & & $\mathbf{P} \mathbf{v}$ & & M] & \begin{tabular}{l|l} 
& 1 \\
\end{tabular} & $1+$ & & $1 \mathrm{v}$ & $\mathbf{N}$ & $|\mathbf{A}| \mathbf{N} \mid+$ \\
\hline ALONSO DE ESPINOSA & \begin{tabular}{|l|l}
$N T$ \\
$N$
\end{tabular} & R & $\mathrm{H}$ & $\mathrm{N}$ & $+\mathrm{E}$ & \begin{tabular}{|l|l|l|l|l|l|l|l}
$E$ & \\
\end{tabular} & & M & +1 & & $\mathrm{E}$ & $\mathbf{N}$ & \begin{tabular}{|l|l|l|l|l|l|}
1 & $N$ \\
\end{tabular} & $1+$ & $+\mathrm{F}$ & M & $\mathrm{E}$ & $A$ & \begin{tabular}{l|l}
$R E$ \\
\end{tabular} & 1 & +1 & \begin{tabular}{l|l}
$N$ & $B$ \\
\end{tabular} & 1 & $\mathbf{M}$ & E 1 & + & A & \begin{tabular}{l|l}
$\mathrm{N}$ & $\mathrm{N}$ \\
\end{tabular} & \begin{tabular}{|l|l|l|l|}
$N$ & $E$ \\
\end{tabular} & & \begin{tabular}{l|l}
$P$ & $E$ \\
\end{tabular} & $E|R|$ & $\bar{F} \mathbf{M}$ & & \begin{tabular}{l|l}
$v$ & 1 \\
\end{tabular} & & \\
\hline \multicolumn{38}{|l|}{ JUAN DE ABREU GALINDO } \\
\hline JUAN N & \begin{tabular}{|l|l|l|}
$N$ & $T$ \\
\end{tabular} & $\mathbf{R}$ & H & $\mathrm{N}$ & $+E$ & E A & & M & & & E & $\mathbf{N}$ & $\mathrm{I}$ & $1+$ & & M & $\mathrm{E}$ & & \begin{tabular}{l|l}
$R E$ \\
\end{tabular} & & & \begin{tabular}{l|l}
$N$ & $B$ \\
\end{tabular} & & M & & & A & & \begin{tabular}{l|l|l}
$N$ & $E$ \\
\end{tabular} & & \begin{tabular}{l|l}
$P$ & $E$ \\
\end{tabular} & \begin{tabular}{l|l|l}
$E$ & $R$ \\
\end{tabular} & $\mathrm{~F} / \mathrm{M}$ & & \begin{tabular}{l|l}
$v$ & 1 \\
\end{tabular} & 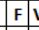 & \\
\hline ATH & \begin{tabular}{|l|l}
$N$ & $T$ \\
\end{tabular} & $R$ & $\mathrm{H}$ & $\mathrm{N}$ & $+E$ & $E A$ & & M & +1 & I & & $\mathbf{N}$ & $\mathrm{N}$ & $1+$ & $+F$ & M & $\mathrm{E}$ & A & \begin{tabular}{l|l}
$R$ & $E$ \\
\end{tabular} & 1 & & \begin{tabular}{l|l}
$N$ & $B$ \\
\end{tabular} & & M & E 1 & + & A & & \begin{tabular}{l|l}
$N$ & $E$ \\
\end{tabular} & & \begin{tabular}{l|l} 
& $E$ \\
\end{tabular} & \begin{tabular}{l|l|l}
$E$ & $R$ & $F$ \\
\end{tabular} & $\mathrm{~F} M$ & & \begin{tabular}{l|l}
$v$ & 1 \\
\end{tabular} & $\mathrm{~F}$ & \\
\hline BARTOL & \begin{tabular}{|l|l|}
$N$ & $T$ \\
\end{tabular} & $R$ & $\mathrm{H}$ & $\mathrm{N}$ & $+E$ & EA & & M & +1 & & & $\mathbf{N}$ & $\mathrm{I}$ & $1+$ & $+F$ & M & $\mathrm{E}$ & A & \begin{tabular}{l|l}
$R$ & $E$ \\
\end{tabular} & 1 & & \begin{tabular}{l|l}
$N$ & $B$ \\
\end{tabular} & & M & E 1 & + & A & $\mathbf{N} / \pi$ & \begin{tabular}{l|l}
$N$ & $E$ \\
\end{tabular} & & \begin{tabular}{l|l}
$P$ & $E$ \\
\end{tabular} & \begin{tabular}{l|l|l}
$E$ & $R$ & $F$ \\
\end{tabular} & M & & \begin{tabular}{l|l}
$v$ & 1 \\
\end{tabular} & $\mathrm{~F}$ & \\
\hline DHN CAMPBELL & 1 & & $\mathrm{H}$ & & & & & $\mathrm{M}$ & & & & $\mathrm{N}$ & $\mathrm{I} N$ & 4 & & M & & & & 1 & & \begin{tabular}{l|l}
$N$ & $B$ \\
\end{tabular} & & M & 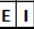 & & & & \begin{tabular}{l|l|l|}
$N$ & $E$ \\
\end{tabular} & & \begin{tabular}{l|l}
$\mathrm{P}$ & $\mathrm{E}$ \\
\end{tabular} & & & & $\begin{array}{lll}v & 1 \\
\end{array}$ & $F$ & \\
\hline
\end{tabular}

Figura 1.3: Comparativa entre los materiales documentales textuales acerca de las letras de la talla de la Virgen de Candelaria.

Queda claro que la mayoría ofrecen coincidencia completa. En los casos donde existe al menos alguna fuente con una variante (color rojo) vemos que se da una altísima cercanía entre las letras: así "F" con "E" en las mayoría de los casos, siete casos; "N" con "M" en un caso; "I" con "T" en otro caso; "I" con "L" en una ocasión; y "P" con "R" en dos ocasiones. No parece que se deban a errores fonéticos, como si se hubieran tomado al dictado de otra persona, sino que son errores de la toma de datos, quizás en la copia primera mirando la talla original, o bien al ser copiado a otro papel en una primera translación o duplicado, o quizás ya en la imprenta como error de linotipista.

Los casos donde alguno de los autores ofrece una letra eliminada/inserta para al menos alguno de los otros (color azul) son en total seis. El caso $2^{\circ}$ parece una situación clara de error por parte de Andrade, quien recoge la interpretación de Kircher, quizás un error de imprenta; el caso $3^{\circ}$ nos parece similarmente una falta por parte de Abreu, sea cual sea la causa, pues encontramos la letra "E" en los demás cuatro autores. Similarmente podemos decir en el $4^{\circ}$ caso para Campbell; el $5^{\circ}$ y el $6^{\circ}$ parecen errores de 
lagunas del obispo Bartolomé y Kircher, existiendo en el resto de autores coincidencia en las letras que el prelado y el jesuita no recogen. Si ahora consideramos la $1^{\mathrm{a}}$ letra, que sólo ofrece García Ximénez, nos es sorprendente, al no encontrarla en nadie más.

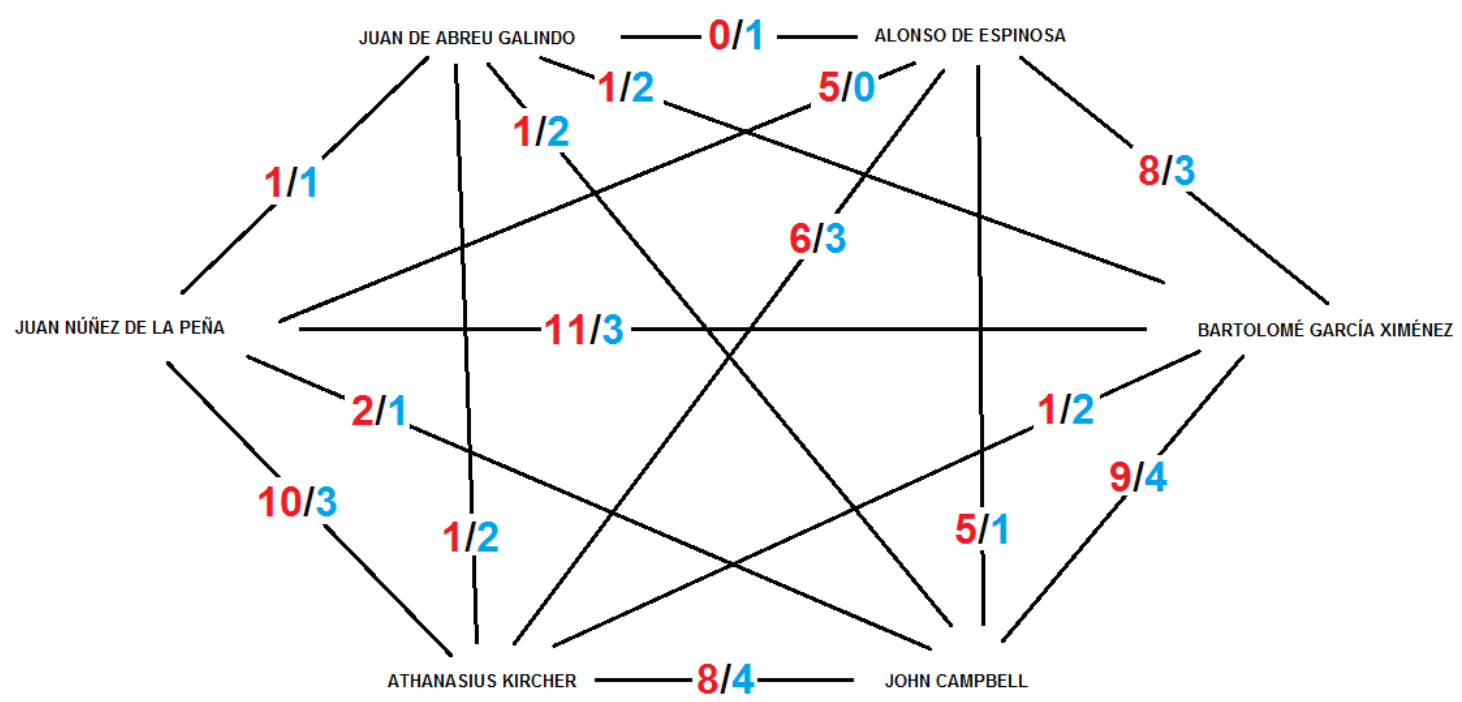

Figura 1.4: Comparativa entre los materiales documentales textuales entre sí en sus variantes-similares/ausencias-inserciones (rojo/azul) acerca de las letras de la talla de la Virgen de Candelaria.

En un simple golpe de vista parece que no podemos decidirnos claramente, si bien tenemos claro que desde cualquier autor podemos responder a las variantes grafémicas del resto de autores. En cuanto a las ausencias o inserciones, lo normal es la ausencia, no la inserción de novedades, sino lo contrario, la omisión, como podemos ver en Abreu, incluso a pesar del texto corto proporcionado por él, o en Kircher, García Ximénez o en Campbell. De ahí que esto nos lleve a pensar en Espinosa o en Núñez de la Peña como los más fidedignos. No olvidemos que Abreu en su relato no parecía mostrar que fuera un testigo directo, siendo muy fiel a Espinosa, por lo que no podemos considerarlo una fuente totalmente independiente del dominico; e igualmente Campbell, que no coincide con ningún otro, y recibió lo que le remitió Juan Bethencourt Alfonso, pero que sin coincidir con el dominico, parece que usó su letrero, aunque se acerca más a Núñez de la Peña, posiblemente debido al uso del dibujo que también recibió junto con el texto del fraile dominico. Sabemos adicionalmente, como ya apuntamos y podemos corroborar, que en el capítulo de la obra de Núñez de la Peña donde trata de la imagen mariana sigue a Espinosa casi literalmente, por lo que no tiene delante la talla y no ofrece su propio relato de lo que ve. Sirva esto también para reflejar que a pesar del cuasi-calco que suponen ambos textos, lo fácil que es caer en errores, como las cinco variantes encontradas entre ellos. En cuanto a las letras que nos refiere Andrade en su obra y que suponemos que son las que usó Athanasius Kircher, S.I., el parecido con las del obispo 
Bartolomé es muy alto, incluso como ya apuntamos al utilizar el juego de mayúsculas y minúsculas "EVPMirNa * ENuPMTI", proviniente del cuasi-acrónimo del prelado en "MIRabilis NAti Eterni NUminis".

Si como todo sugiere Núñez de la Peña copia a Espinosa, podemos pensar que el error en el cambio de la "N" por la "M" sea un fallo particular, pero lo encontramos en Campbell; no obstante, teníamos el dato de que Campbell seguía a Espinosa, pero más bien parece que sigue a Núñez de la Peña, al tener con él mayor cantidad de coincidencias: dos frente a cuatro. Esto se resuelve teniendo en cuenta que el escocés John Campbell usó de las letras de Espinosa, según nos refiere el historiador José Rodríguez Moure, junto con alguna estampa de la talla mariana, de la que suponemos seguía otra variante, que ahora no podemos precisar. Si intentamos ver la línea causal del obispo García, tiene con Espinosa en cuanto a variantes grafémicas (color rojo) ocho frente a las once que tiene con Núñez de la Peña. Además, presenta similitudes con el dominico allí donde Núñez de la Peña ya alteró la grafía de la letra. No parece descabellado pensar que Espinosa es origen de Abreu, Núñez de la Peña y García Ximénez (y este último de Andrade-Kircher); y que Campbell seguía a Espinosa y otra variante alterada proveniente de alguna imagen gráfica de una estampa o grabado.

Si con todo lo dicho las letras de fray Alonso de Espinosa, O.P. son las más fiables, hemos de recordar que de él apuntamos que es un fiel relator, e intentó ser tan serio y preciso como pudo, también en cuanto a lo que refiere al origen, significado, descripción y letras de la imagen. Además, al carecer el archipiélago de imprenta hubo de desplazarse a Sevilla donde imprimió su escrito, por lo que entendemos, al no existir otras segundas impresiones, que esta era suficientemente buena y acorde, aspectos que controlaría en la misma imprenta de la "casa de Juan de León, junto a las siete Rebueltas", como anota la portada al comienzo y el colofón al final de su obra[?]. Ningún autor posterior, incluso los que quisieron denigrarlo, mencionan posibles equívocos en su copia de las letras, como la familia descendiente de Hernando Esteban Guerra (ca. 1490-1552), al no salir bien parados en la obra del fraile, por lo que al parecer costearon la publicación de Viana para defenderse cambiando el pasado, y quizás eliminaron tantos ejemplares como pudieron de la obra de Alonso de Espinosa, quedando escasos de ellos en el siglo XVIII, y asimismo en la actualidad: sólo seis de la primera edición de 1594, no habiendo otras ediciones hasta el año 1848, muy incompleta; otra en el 1907, en inglés, también con lagunas en el texto, así como la de 1940 (reimpresa en el 2001) en castellano, pero con ausencias de partes; y posteriormente, las de 1952, 1967 y 1980, completas y fieles al original de 1594[?][?]. Y qué mejor razón para eliminar sus ejemplares y así salvar el honor de los sucesores del conquistador Hernando Esteban Guerra que afirmar los errores en los letreros de la talla. Pero ni ellos ni nadie afirmaron nunca tal cosa. A favor de Espinosa está también el hecho de haber sido el que más cerca de la talla convivió, moviéndola, limpiándola, vistiéndola y desvistiéndola para las diversas procesiones, romerías, actos de culto, etc., como nos dice, comentándonos que ni el propio obispo Fernando Xuárez de Figueroa la llegó a ver desnuda de ropajes y telas en su visita pastoral, tal y como apareció, siendo el vestirla y el desvestirla algo que el dominico nos relata hizo " $m i l$ veces"[?]. Por todo ello será nuestra principal y fundamental referencia a cuanto al texto se refiere, al menos en este momento de nuestro estudio. 


\section{Capítulo 2}

\section{CONCLUSIONES}

Hemos ofrecido una propuesta de significado a la inscripción de la talla original de la Virgen de Candelaria. Se han considerado otras propuestas y solamente una de ellas, se acerca a la nuestra, tal y como hemos mencionado en el capítulo X. No obstante, nuestra solución, consideramos, mejora todas las precedentes, ofreciendo un apoyo de contexto mucho más depurado y sólido.

Antes de ello hemos concluido con altísimo grado de certeza no ser el texto de la inscripción de la talla de Candelaria el resultado pseudo-aleatorio o sin sentido alguno colocado sin pretensión alguna en la talla. Hemos también mostrado con gran certidumbre el no ser resultado de un proceso criptológico y esteganológico alguno. No es por lo tanto un texto enigmático u oscuro.

Tras un análisis meticuloso de posibles lenguas base hemos situado el texto no solamente en una lengua, sino en una lengua desaparecida y extinta, una forma arcaica de bereber cuyo conocimiento hoy, siendo escaso, nos ha sido suficiente para eliminar otras hipótesis.

Los datos de contexto, ya de la historia, el arte, las creencias, ya aborígenes canarias como cristianas, los procesos de contacto europeo con los habitantes del archipiélago canario, entre otras, han sido el marco de comprensión de multitud de preguntas a las que hemos ido respondiendo con mayor o menor dedicación, sin olvidar nuestro cometido principal, permitiéndonos situar de manera acabada y completa el significado logrado a la inscripción de la talla de la Virgen de Candelaria. 


\subsection{LÍNEAS FUTURAS}

Esta investigación ha intentado eliminar este apartado en la tesis pretendiendo resolver todos los problemas planteados, sin embargo, los problemas nunca pierden toda su potencialidad, jamás están resueltos completamente, y en ocasiones generan problemas menores o anexos de gran magnitud junto con las soluciones encontradas.

Mostramos a continuación con brevedad, pues son multitud los temas, especialidades y disciplinas aquí consideradas y tratadas, las principales líneas futuras de investigación aún pendientes más o menos parcialmente.

- Es preciso profundizar en las fuentes documentales para poder circunscribir con la mayor pureza y certidumbre los acontecimientos relativos a la talla original mariana de Candelaria. Esto significa resolver y depurar, al tiempo que explicar, los errores e incoherencias, así como sus fuentes posibles y causalidades, en los datos referentes a la aparición, el momento y lugar, los actores involucrados, el proceso de permanencia en el ámbito indígena canario, la relación con la cueva del Cañizo o de invierno frente a las más estudiadas de Chinguaro y Achbinicó, y la averiguación de su existencia por parte hispana, así como la trazabilidad de la misma imagen en las primeras décadas de su existencia.

- Ligado a lo anterior se hace preciso fundamentar en las fuentes documentales artísticas especialmente, pues creemos que en las textuales el conocimiento es mucho más claro, tal y como aquí hemos mostrado, el proceso de copiado y realización de las diferentes obras pictóricas, escultóricas, grabados, etc. de la imagen de Candelaria, lo que nuestra investigación ha llevado a concluir como un continuado reproducirse de unas a otras y una adición de errores encadenados que aparecen en sucesivos retratos y figuraciones, si bien en ocasiones creemos que se usa de más de una fuente. Este proceso debiera estar mejor clarificado, permitiéndonos englobar qué obras y qué fuentes textuales son más fieles a las letras originales de la talla. Otro aspecto, para nuestro interés de menor importancia, es catalogar el conjunto de inscripciones diversas que la original cartelería ha llevado con el paso del tiempo a crear y recrear.

- A pesar del indudable valor del análisis artístico del profesor Jesús A. M. de C. Hernández Perera en el año 1975 sobre la talla, creemos que debería volverse en su misma línea a intentar perfilar y matizar, o al menos refrendar y seguir ratificando, lo allí expresado en cuanto a lo afirmado en su análisis de la imagen.

- Algunas tallas como la Virgen del Pino o de los Remedios, o el Cristo de la Laguna, todas del archipiélago canario, con inscripciones todas ellas, precisan de un estudio de las mismas y sus letras y una posible o no relación con la de Candelaria o entre ellas. Una ampliación a otras obras fuera de las islas también es un aspecto a considerar en el futuro. 
- Creemos necesario un estudio del lecho marino costero de la playa de Candelaria mediante examen de arqueología subacuática para responder al destino de la talla tras el aluvión del 1826. No ha sido realizado un meticuloso análisis de restos allí depositados y se precisa de un escudriñado y rastreo del material allí aún presente y responder al modo como la talla sufrió el ataque de agentes físico-químicos y biológicos.

- Relativo al contexto, son muchos los campos abiertos. Ciertamente que hemos apuntado a la figura de fray Juan de Logroño, O.F.M. como vicario franciscano a la hora de hablar de un origen en la idea de confeccionar la talla de Candelaria, pero no podemos negar que no tenemos una certeza completa, y mucho menos un documento o mención directa o indirecta, si es que lo hay, que arroje pistas sobre este aserto. Este dato debe ser mejor dilucidado si es mantenido, o bien proponer una propuesta alternativa mejor y más coherente.

- Junto con lo anterior, se debe profundizar en las condiciones relativas a la fecha y lugar de la aparición, el taller donde se realizó la talla, el motivo, la intención, la finalidad, si se intentaron procedimientos previos diferentes pero parecidos a este de contacto catequético con los isleños, con otras islas, o bien con regiones de Berbería u otras zonas de África, o con territorios paganos de Europa o Asia, aspectos de misionología y de inculturación, así como de la religiosidad, la teología y las ciencias matemático-astronómicas de los pueblos insulares canarios, que arrojaran luz en los modos considerados en extenso en el capítulo IV de nuestra tesis.

- Es necesario ampliar el conjunto de textos para las lenguas analizadas y extender nuestro estudio a la totalidad de las lenguas, configurando un corpus de porcentajes grafémicos y fonéticos así como de Índices de Coincidencia de gramas en todos los filos existentes, incluyendo las lenguas desaparecidas y de las que tengamos documentos, así como de evolución según épocas. Creemos, como aquí hemos podido mostrar, ser un aspecto de enorme utilidad para el estudio lingüístico y de desciframiento.

- Creemos que se ha de profundizar en la sistematización de métodos criptográficos tal y como la hemos propuesto, y elaborar un tratado más compacto y generalista, que aquí sólo hemos podido esbozar desde el ejemplo del texto Candelaria, permitiendo confeccionar un manual de criptoanálisis completo más allá de la mezcla incompleta y deslavazada de métodos hoy disponibles, que además ha llevado a una ruptura a partir de los métodos asimétricos de criptografía y a dejar el resto de sistemas precedentes como simple propedéutica del pasado no dándoles cabida dentro de los métodos digitales hoy disponibles. Hemos esbozado en nuestra tesis, creemos, un inicio en la dirección que debe seguirse.

- En línea con lo anterior podrían implementarse nuevos métodos de ataque a los considerados en nuestra investigación en los diferentes sistemas de criptoanálisis y mejorar los implementados y desarrollados. 
- En referencia a los métodos de pseudo-aleatoriedad son líneas siempre en estudio y profundización el mejorar los métodos de caracterizarla y generar nuevos métodos de afirmación y refutación de la misma.

- Centrándonos ahora en el ámbito bereber, el primer aspecto sería mejorar el conocimiento de la procedencia de los pobladores primeros de las islas y número y momento de las arribadas.

- Cuestión pendiente es el mejor conocimiento de las lenguas bereberes y del proto-bereber, así como de la evolución de la lengua en el ámbito insular canario en todos sus aspectos lingüísticos y filológicos.

- Nos ha sorprendido la gran cantidad de textos presentes en obras artísticas que hoy permanecen sin solución en cuanto a su significado. Algunos parecen no tener significado, si bien otros apuntan en dirección contraria. En nuestra investigación hemos resuelto, en mitad del recorrido de nuestra tesis, dos de ellos, desconcertadamente no resueltos. Creemos que es un campo interdisciplinar que precisa de mayor dedicación.

- Finalmente, en referencia a la solución propuesta al significado de la talla, es necesario corroborar, contrastar, refutar, modificar, perfilar, negar o afirmar, parcialmente, fragmentariamente, o en su totalidad, la respuesta por nosotros dada. Asimismo, apoyar desde todo el contexto y la semántica el conjunto de raíces y voces amazigh más acordes a la inscripción de la talla original de Candelaria. 


\subsection{CONTRIBUCIONES}

A día de hoy no se ha enviado para publicar ningún artículo o escrito en ninguna revista especializada. Tampoco se ha presentado en ningún congreso nacional o internacional resultado alguno aquí logrado. Queda para la fecha después de la defensa de esta tesis la publicación de resultados en diversas revistas científicas, la realización de algunas presentaciones en congresos y quizás la publicación de algún texto en formato de libro de aquellos resultados más sobresalientes alcanzados.

Seguidamente recogemos de manera sucinta las contribuciones y logros más destacados alcanzados en nuestra investigación:

- Hemos recogido todo el material documental textual referente a las inscripciones de la talla primera y original de Candelaria, realizando un análisis de sus divergencias y parecidos, estableciendo entre todos los autores y menciones una posible causalidad que permita explicar las variaciones encontradas, y remontarnos con la máxima certeza al conjunto literario primigenio.

- Al mismo tiempo hemos realizado un amplio análisis de la obra artística, fuentes documentales también junto con las anteriores, que muestran en su obra pictórica, escultórica, de grabado, orfebrería, etc. las letras objeto de nuestro estudio. Hemos mostrado las líneas causales entre ellas y la cercanía mayor o menor a la fuente original, así como la posibilidad de uso por parte del artista de la talla original en su realización, o bien la copia desde otra creación de un artista precedente.

- Con todos los datos precedentes de ambas fuentes, ya documentales o impresas, como artísticas, hemos concluido en la que puede considerarse la más fiel de las fuentes y la más fiel de la secuencia de letras de la talla original de Candelaria.

- En referencia a la talla de Candelaria de Adeje, objeto de tanta polémica, hemos analizado su secuencia literal y establecido su relación con la original de Candelaria, al tiempo que mostrado su construcción a partir de un conjunto muy pequeño de unidades grafémicas, con gran parecido con la original, y la posterior sobreabundancia y repetición hasta elevar en alrededor de cinco veces su redundancia. De esta forma concluimos su posterioridad y su dependencia con la talla primera de Güímar.

- De manera también inédita hemos mostrado la secuencia de acontecimientos sufridos por la talla durante el aluvión del año 1826 en la cual se perdió, y el conjunto de hipótesis más probables referentes a su paradero y los procesos sufridos a partir de entonces, concluyendo en la total pérdida de la misma.

- Hemos introducido dentro del estudio de contexto de nuestra talla aspectos relativos no sólo a los pobladores, los contactos con otros pueblos, el redescubrimiento y la conquista, sino además, la misión y evangelización, 
la importancia de las corrientes dentro del franciscanismo (observantes y conventuales), y los métodos de evangelización posterior en América, con el fin de explicar el significado de la talla, el porqué de la misma, su advocación, la finalidad, el propósito, la fecha, el destino, sus destinatarios, e incluso dando un posible autor de la misma. Muchos de los aspectos recogidos en esta tesis en esta sección no son propios, sino que han sido recogidos de multitud de autores e investigadores, sin embargo, creemos que hemos ofrecido una mejor respuesta en cuanto a la autoría de la realización de la talla explicando con ello las circunstancias de los hechos acaecidos y la fecha probable de su abandono y aparición en las playas de Chimisay.

- Hemos recopilado para un conjunto de 101 lenguas 261 textos en diferentes épocas (en especial los siglos XIV y XV, o cercanos a ellos) que nos han servido de base documental para establecer un cuerpo de datos grafémicos y fonéticos de nueve filos además de lenguas no clasificadas, permitiéndonos disponer de diferencias porcentuales y de Índices de Coincidencia entre ellas, ya intra-lingüísticas como inter-lingüísticas. Este elenco, de indudable valor filológico y lingüístico, es único en el mundo y permite disponer de una base comparativa antes nunca disponible.

- Hemos desarrollado sobre dos metodologías de análisis de gramas (grafemas y fonemas) del conjunto de datos del corpus anterior, herramientas de suficiencia y análisis para distinguir la pertenencia de un texto cualquiera a alguna lengua posible del conjunto.

- Por otro lado, hemos ampliado al estudio de los fonemas los habituales estudios de porcentajes y de I.C. de grafemas. Tal y como hemos visto en nuestra investigación, el examen grafémico es insuficiente en muchos casos y situaciones donde se ve involucrado un proceso de transcripción.

- En el aspecto criptológico destacamos en primer lugar en análisis del contexto histórico para poder entender el conjunto de posibilidades disponibles para el supuesto ciframiento del texto de la talla.

- Resaltamos nuestra ordenación de métodos y sistemas de criptología, diferente a la existente hoy en día, y más en la línea de los trabajos de los especialistas musulmanes de la Edad Media y del Renacimiento. Creemos que la introducción del cifrado asimétrico, si bien un enorme y potentísimo logro intelectual, ha desenfocado el conjunto de sistemas dentro de la criptografía. Nosotros mostramos una ordenación algebraica compacta donde situamos todos y cada uno de los métodos, incluyendo aspectos de redundancia y sus respectivas funciones como sistemas pre-criptológicos. Todo esto nos permite establecer un ordenado conjunto además de completo, que redefine, creemos, mucho mejor todos los procedimientos posibles, incluyendo los métodos de cifrado asimétricos, que resitúa en su lugar propio. Por otro lado, agrupamos las operaciones lógico-aritmético-algebraicas en un conjunto apropiado. Finalmente, y en línea con la intuición de Claude Elwood Shannon y Horst Feistel, avanzamos un paso más en la comprensión de las propiedades de confusión y difusión, derivándolas de un método general de toma 
o asignación, lo que nos permite una mayor comprensión de su relación, en cierto aspecto inversa.

- Realizamos sobre el texto de la inscripción de la talla un exhaustivo y completo análisis criptoanalítico de todas las opciones posibles antes mencionadas en base al estudio histórico realizado, con multitud de métodos nuevos de ataque, ya en la eliminación, la inserción, la transposición o las sustituciones, recogiendo las posibilidades de composición y los métodos esteganográficos. Todo este conjunto de procedimientos nos permiten hablar de un tratado, en base eso sí, a un ejemplo concreto, de criptoanálisis, con métodos en gran parte novedosos y nunca antes aplicados en la historia de la criptografía.

- Mencionar también como una contribución más la ampliación del habitual Índice de Coincidencia de orden 1 al orden 2 y orden 3 , realizado una generalización a orden $n$ del mismo.

- Otra de las contribuciones de esta investigación es el conjunto de métodos que hemos aplicado al estudio de la pseudo-aleatoriedad de la inscripción, tanto para el conjunto como para las partes, así como el sorprendente resultado del análisis de Sukhotin al obtener tres vocales del texto.

- Nuestro aporte propio al conjunto de datos que recopilamos y recogemos de otros investigadores sobre la lengua y la etnia bereber es la necesidad del análisis semántico de la festividad de la Purificación o de la Presentación (Candelaria), tanto a nivel litúrgico y teológico como artístico, así como el examen también dentro del Arte de las inserciones de muestras literarias en lengua latina, en otras lenguas, con semántica o no, pseudo-grafémicas, asemánticas y enigmáticas, necesario para situar nuestra imagen en su contexto y significación.

- Dentro del conjunto que hemos considerado en la sección correspondiente en el capítulo IX resaltamos la resolución propuesta por nosotros de la secuencia "DIER ZVO LIEB 100" de la "Adoración de los Magos" de Bartholomäus Zeitblom, del año 1494, que tenemos en la iglesia abacial de san Johannes Evangelista en Blaubeuren, Alemania, hasta hoy incompleta en su sentido. La otra solución textual dentro del arte que damos es la referente a la obra "Virgen María" y "El Salvador", de Quentin Massys, obra díptica del año 1529 y que encontramos en el Museo del Prado de Madrid, en España. Se suponía ser un texto pseudo-grafémico, si bien hemos dado con una solución altamente consistente y perfectamente legible en lengua hebrea.

- Como colofón de las aportaciones de nuestra investigación destacar la solución que ofrecemos, junto con las precedentes señaladas de otros autores, y que consideramos la más acorde y coherente explicación del significado de la inscripción de la talla de Candelaria.

- Por último, y de manera conjunta a toda la tesis, recoger en este apartado la 
metodología seguida, ya referida en la sección inicial de la tesis: la importancia de proceder en la investigación no de manera parcial, sino enfocando el problema desde multitud de disciplinas, ya desde la historia, el arte, la teología, la lingüística, o la criptología, como medio necesario para poder entender un problema y con ello atisbar una solución al mismo. 